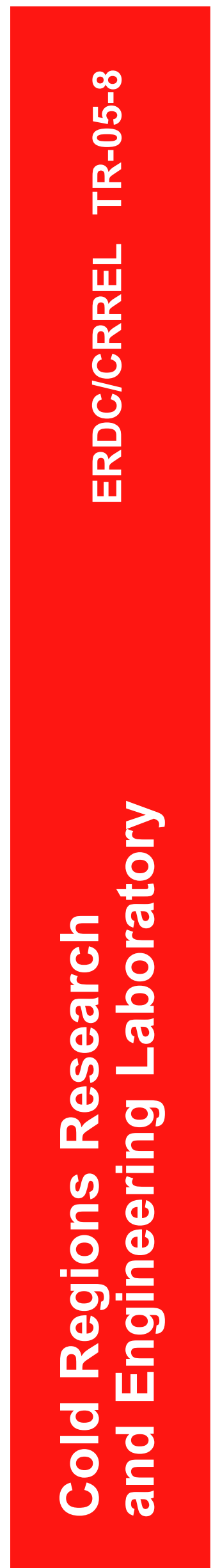

\title{
An Examination of Protocols for the Collection of Munitions-Derived Explosives Residues on Snow-Covered Ice
}

Michael R. Walsh, Marianne E. Walsh, Charles A. Ramsey, and Thomas F. Jenkins 
COVER: Sampling in the pre-dawn light at Eagle River Flats, January 2004. Sampling bias is evident in this image as the samplers follow the darkest segment of the plume from the detonation point toward the edge of the plume. The second bag at each sampling location is the subsurface sample. (Photo by C.A. Ramsey) 
ERDC/CRREL TR-05-8

April 2005

\section{An Examination of Protocols for the Collection of Munitions-Derived Explosives Residues on Snow-Covered Ice}

Michael R. Walsh, Marianne E. Walsh, Charles A. Ramsey, and Thomas F. Jenkins

Engineer Research and Development Center

Cold Regions Research and Engineering Laboratory

72 Lyme Road

Hanover, New Hampshire 03755

Approved for public release; distribution is unlimited.

Prepared for OFFICE OF THE CHIEF OF ENGINEERS 


\section{ABSTRACT}

Range contamination and sustainability are major issues for the United States military. Training is a critical factor in force readiness, and the availability of ranges is crucial to this need. To determine the impact of training on ranges, data are required on the deposition of explosives residues from live-fire and blow-in-place detonation of munitions. A method of sampling on snow-covered ranges, the discrete sampling method, was developed by the Army's Cold Regions Research and Engineering Laboratory to determine residues from the detonation of munitions. Although very effective, it requires the collection of many large samples, resulting in labor-intensive field operations and much processing and analysis work in the laboratory. By examining sampled locations within detonation plumes, it appears that collection bias may be affecting the results. There was also no methodology for quality assurance in the collection of the samples. We have examined the process currently in use and carried out a series of experiments to determine whether bias and sample quality issues are present in the sampling technique. Alternative methods of sample collection that afford a greater opportunity for quality control were examined and compared to the discrete sampling method. The recommended alternative sampling protocol is to collect multi-increment samples, and experimental results using this method are presented.

DISCLAIMER: The contents of this report are not to be used for advertising, publication, or promotional purposes. Citation of trade names does not constitute an official endorsement or approval of the use of such commercial products. All product names and trademarks cited are the property of their respective owners. The findings of this report are not to be construed as an official Department of the Army position unless so designated by other authorized documents. 


\section{CONTENTS}

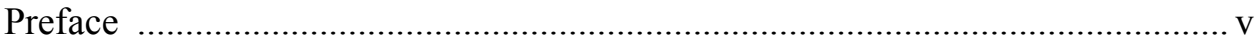





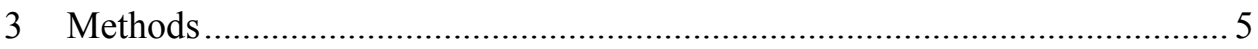



Application and Confirmation Tests ......................................................... 9

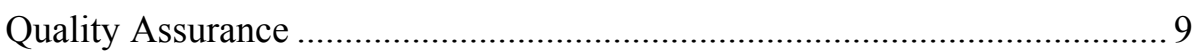



I. Protocol Tests_-The Discrete Sampling Method ....................................... 12

II. Protocol Tests-Alternative Sampling Methods ..................................... 22

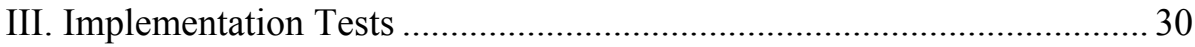

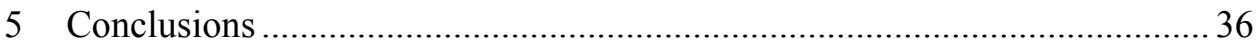

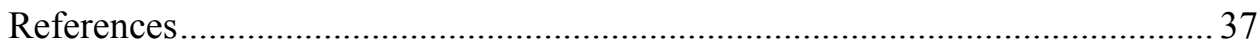

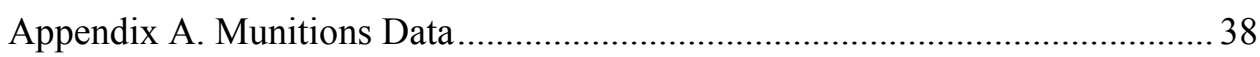

Appendix B. Quality Assurance Procedures for Protocol Tests ......................... 41

Appendix C. Data for the Discrete Sampling Method Tests............................... 48

Appendix D. Data for Protocol Tests................................................................... 53

Appendix E. Data for Implementation Tests ...................................................... 56

\section{ILLUSTRATIONS}

Figure 1. Eagle River Flats, location of the tests 3

Figure 2. Test setup for detonation of 81-mm mortar rounds and 105-mm howitzer rounds 6

Figure 3. Detonation setup for $155-\mathrm{mm}$ implementation tests............................ 10

Figure 4. Sampling diagrams for outside-the-plume sampling ........................... 11

Figure 5. Replicate discrete sampling on Plume 81-3 ….................................. 18

Figure 6. Collecting adjacent MIS samples and subsurface samples from 155-mm plume 


\section{TABLES}

Table 1. Testing conducted for sampling protocol study ....................................5

Table 2. Test execution for sampling protocol tests ............................................ 7

Table 3. Test execution for protocol application tests ........................................ 9

Table 4. Quality assurance procedures ............................................................. 10

Table 5. Detonation plume data for DSM tests................................................. 12

Table 6. Underreporting of total mass residues due to sampling depth error ...... 14

Table 7. Results of sampling outside the visible plume..................................... 15

Table 8. Detonation proximity bias in DSM sample location............................. 16

Table 9. Detonation proximity bias (unweighted vs. weighted) in DSM

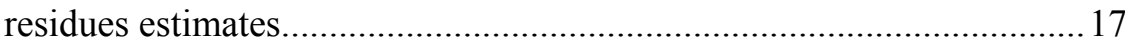

Table 10. Soot density bias in DSM residues estimates, Plume 105-4 …........... 17

Table 11. Comparison of DSM samples for Plume 81-3 .................................... 19

Table 12. Data for crater components (RDX) ….............................................. 21

Table 13. Comparison of DSM and adjacent sampling ...................................23

Table 14. Relative percent differences in calculated residue values between averaged MIS and composited DSM sampling...................................25

Table 15. Replicate comparisons for MIS samples..........................................2

Table 16. Relative percent differences in calculated residue values between averaged LIS and composited DSM sampling .....................................28

Table 17. Results of concentric zone sampling of three plumes ..........................2 29

Table 18. Comparison of gray-zone results, Plume 105-4 _..................................2 29

Table 19. Analysis of plume samples-155-mm Comp-B rounds ..................... 31

Table 20. Data for crater samples-155-mm Comp-B rounds ............................. 32

Table 21. Analysis of plume samples-155-mm TNT rounds ............................ 34

Table 22. Sampling QA non-plume analysis for TNT-filled 155-mm






\section{PREFACE}

This report was prepared by Michael R. Walsh, Mechanical Engineer, Engineering Resources Branch, Engineer Research and Development Center, Cold Regions Research and Engineering Laboratory (ERDC-CRREL), Hanover, New Hampshire; Marianne E. Walsh, Chemical Engineer, Environmental Sciences Branch (ESB), ERDC-CRREL; Charles A. Ramsey, EnviroStat, Fort Collins, Colorado; and Dr. Thomas F. Jenkins, Research Chemist, ESB, ERDCCRREL.

Major funding for this project came from three sources: Strategic Environmental Research and Development Program through Compliance Project 1155, Distribution and Fate of Energetics on DoD Test and Training Ranges, through Dr. Judith Pennington of EL and Dr. Tom Jenkins of CRREL; the Minimization of Explosive Residues in Blow-in-Place Procedures Distributed Sources work unit sponsored by the Corps of Engineers Environmental Quality and Installations Program, Focus Area for Characterization/Assessment of Distributed Source Ordnance-Related Compounds on Ranges; and funding received from the USA Engineer and Support Center, Huntsville, under the CEHNC OE Initiative Tech Program though Ms. Deborah Dixon Walker.

The work upon which this report is based involved many people across several entities. At Fort Richardson, Mr. L.D. Fleshman and the staff at Range Control provided range access during a very busy period of training. The soldiers of the 4/11th provided engineering demolitions support for the detonation of the rounds. Jeff Lipscomb of the Army Cold Regions Test Center at Fort Greely coordinated the acquisition and delivery of the rounds used during testing. Ken Wright and James Ratcliff of Clearwater Environmental provided assistance with the demolitions and UXO support.

For the tests, the authors had field assistance in January from Alan Hewitt, Dr. Jon Zufelt, Charlie Collins, and Kevin Bjella of CRREL, along with Captain Adrian MacCallum of the Australian Army. In March, the authors were joined by Dr. Tom Douglas of CRREL, Tommie Berry of EL, and Drs. Sonia Thiboutot and Guy Ampleman of Defense Research and Development - Canada (Valcartier, Quebec). For both deployments, Nancy Perron, Dennis Lambert, and Charlie Schelewa set up and operated the site lab. Major Doug Anderson of CRREL oversaw demolitions operations. JoAnn Walls of the Corps of Engineers, Alaska District, provided critical contracting support. Extensive project support was provided by the U.S. Army Alaska.

Technical review of this report was provided by Dr. Susan Taylor of CRREL and Dr. Clarence L. Grant. 
This report was prepared under the general supervision of Thomas J. Tantillo, Chief, Engineering Resources Branch, and Dr. Jean-Claude Tatinclaux, Chief, Environmental Sciences Branch, CRREL; Dr. Lance D. Hansen, Deputy Director, CRREL; and James L. Wuebben, Acting Director, CRREL.

The Commander and Executive Director of the Engineer Research and Development Center is Colonel James R. Rowan, EN. The Director is Dr. James R. Houston. 


\title{
An Examination of Protocols for the Collection of Munitions-Derived Explosives Residues on Snow-Covered Ice
}

\author{
MICHAEL R. WALSH, MARIANNE E. WALSH, \\ CHARLES A. RAMSEY, AND THOMAS F. JENKINS
}

\section{$1 \quad$ INTRODUCTION}

Range contamination and sustainability are major issues for the United States military. Training is a critical factor in force readiness, and the availability of ranges is crucial to this need. To determine the impact of training with munitions on military ranges, data are required on the efficiency of both live-fire and blowing in place of munitions. Current lawsuits against the Army claim that residues resulting from the use of these ranges are contaminating local groundwater sources. Reliable data are necessary to assess the merit of these claims.

A method of residues sampling on snow-covered ranges was developed by the U.S. Army Corps of Engineers Cold Regions Research and Engineering Laboratory (CRREL) (Jenkins et al. 2000, 2002). Although very effective, it requires the collection of many large snow samples, resulting in slow, laborintensive field operations and much processing and analysis work in the laboratory. From an examination of sample locations, it appears that there may be a bias toward sampling in areas where the residue plume is darkest, which may skew the results. There was also little done in the past for quality assurance as the sampling process was so laborious.

Soil sampling on firing points at the Donnelly Training Area in central Alaska between 2001 and 2003 (M.E. Walsh et al. 2005) indicates that multipleincrement sampling for residues is an effective method for characterizing a site for explosives. This work was conducted during the summer, but we hypothesized that the methods used could be effectively applied to winter sampling of residues on snow. Residue sampling on snow following a winter live-fire exercise at the U.S. Army's Fort Richardson, Alaska, Eagle River Flats impact range (Hewitt et al. 2003) indicated that this area would be ideal for testing our hypothesis. In 2004, two sets of tests were designed and carried out. 
The first set was designed to compare the then-current method of sampling residues from the surface of snow with sampling methods similar to those used at Donnelly. The second set of tests was used to confirm the validity of our choice for the most effective sampling method.

Snow-covered ice is the ideal medium on which to conduct residues tests. The ice cover isolates past residues deposition from current residues in areas where no recent detonations have occurred. The snow cover provides a highly contrasting surface from which to sample. The general detonation plume area delineation is thus facilitated. The snow and ice also isolate the residues from most vegetation and soils, making sample processing easier. 


\section{PHYSICAL SETTING}

Eagle River Flats (ERF) is an estuarine salt marsh located at the mouth of the Eagle River, along the upper Cook Inlet near Anchorage, Alaska (Fig. 1). The Flats have been used as an artillery and mortar impact range for Fort Richardson since the late 1940s. This small, 865 -ha range is periodically flooded by the second-highest tides on Earth. In the winter, the area freezes over and is covered with snow. Temperatures are moderated by the open waters of the inlet throughout the winter months and generally remain below freezing from late November through mid-March.

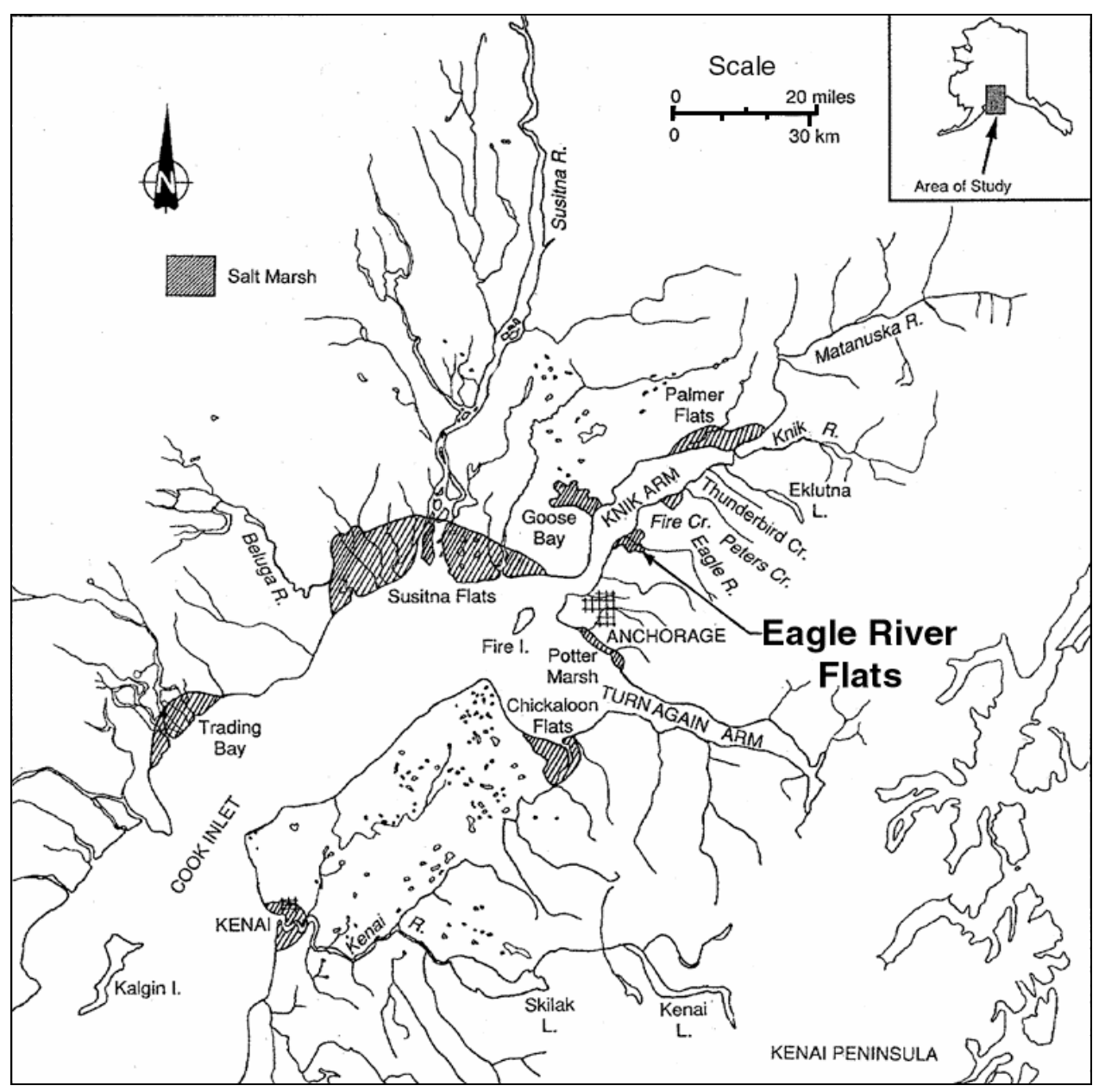

Figure 1. Eagle River Flats, location of the tests. 
Ice thickness and snow cover on the flats vary according to several parameters. Temperature is an obvious factor, but snow cover is critical to limiting ice depth and the freezing of the ground beneath the ice sheet. The frequency and severity of the flooding tides thickens the ice sheet. Wind will influence the snow depth and heat transfer. Normally, an ice sheet sufficiently thick to prevent penetration of live-fired rounds up to $105-\mathrm{mm}$ is attained by midDecember (Collins and Calkins 1995).

The ice sheet is grounded in most areas and is of sufficient thickness to allow traverse by heavy vehicles. Vehicular access throughout the eastern half of the Flats in winter allows efficient testing and operations over a large area. Access to post from ERF is via a well-maintained road, and laboratory facilities are located within $10 \mathrm{~km}$ of the test area. 


\section{METHODS}

Sampling protocol tests were carried out in two phases in conjunction with research into the quantification of explosives residues resulting from the detonation of military munitions. Tests in January 2004 on 81-mm mortar rounds and 105-mm artillery rounds focused on the comparison of alternative sampling methods with the discrete sampling method (DSM) currently in use. The tests in March 2004 using 155-mm artillery rounds looked at the application of the proposed new sampling method. All tests were conducted on fuzed static rounds, employing the standard blow-in-place method used by the Army to dispose of dud rounds found on ranges and battlefields. Table 1 outlines these tests. Appendix A contains more detailed information on the munitions.

\begin{tabular}{|l|l|l|l|}
\hline \multicolumn{4}{|c|}{ Table 1. Testing conducted for sampling protocol study. } \\
\hline \multicolumn{1}{|c|}{ Test/date } & \multicolumn{1}{|c|}{ Munition } & \multicolumn{1}{c|}{ Filler } & \multicolumn{1}{c|}{ Objectives } \\
\hline $\begin{array}{l}\text { Comparative tests } \\
\text { (January 2004) }\end{array}$ & $\begin{array}{l}\text { 81-mm mortar rounds with } \\
\text { point-detonating fuze and }\end{array}$ & $\begin{array}{l}\text { Composition B } \\
\text { 105-mm artillery rounds }\end{array}$ & $\begin{array}{l}\text { 1) Develop quality assurance } \\
\text { methods for winter residues } \\
\text { sampling. }\end{array}$ \\
& with point-detonating fuze & $39 \%$ TNT & 2) Verify validity of then-current \\
& & $1 \%$ wax & sampling method (DSM). \\
& & & 3) Develop protocols for \\
& & & alternative sampling methods. \\
& & & 4) Compare sampling method \\
& & & results. \\
& & 5) Determine best sampling \\
& & & method. \\
\hline $\begin{array}{l}\text { Application and } \\
\text { confirmation tests }\end{array}$ & 155-mm howitzer rounds & Composition B & 1) Refine QA techniques. \\
(March 2004) & and TNT & 2) Test sampling method \\
& & & implementation. \\
\hline
\end{tabular}

All tests used 0.57-kg blocks of C4 (91\% RDX, 9\% plasticizers) initiated with non-electric blasting caps as the donor charge. The $\mathrm{C} 4$ was set alongside the body of the round for the 81-mm detonations and near the fuze on the $105-\mathrm{mm}$ and 155-mm rounds (Fig. 2). Up to seven rounds were detonated and sampled each day. 


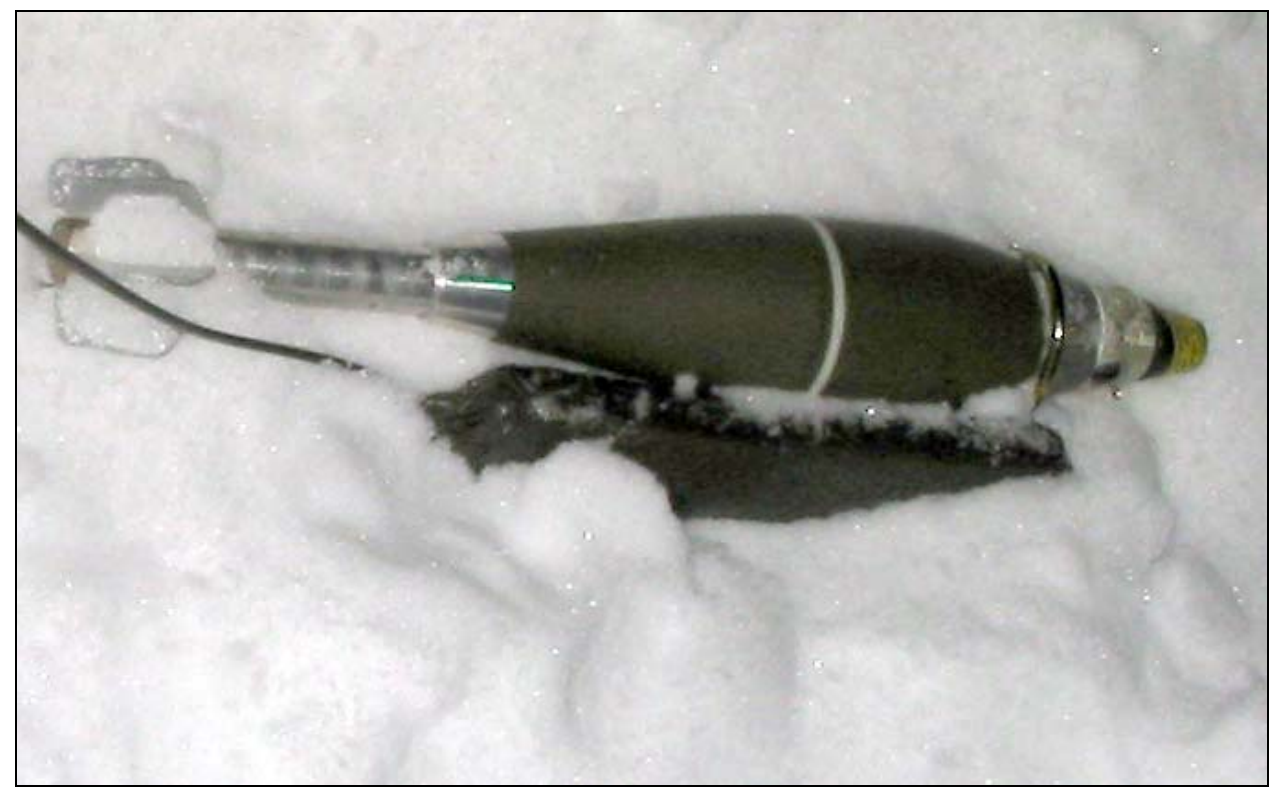

a. 81-mm fuzed round with $\mathrm{C} 4$ donor charge.



b. 105-mm fuzed round with C4 donor charge.

Figure 2. Test setup for detonation of $81-\mathrm{mm}$ mortar rounds and $105-\mathrm{mm}$ howitzer rounds. 


\section{Comparative Tests}

Comparative tests were conducted from 14 to 17 January. Snow depth was more than normal, $33 \mathrm{~cm}$. Temperatures hovered around $-35^{\circ} \mathrm{C}$ in the mornings with light winds of under $1.3 \mathrm{~m} / \mathrm{s}$. Trace amounts of light snow fell sporadically during the first day, but not enough to interfere with the sampling. A weak sun behind a partially overcast sky had no influence on the plumes. Table 2 outlines the test schedule as executed.

\begin{tabular}{|c|c|c|c|}
\hline Date & Munition & Quantity & Tasks \\
\hline 14 January & 81-mm mortar & 2 & Detonation and sampling \\
\hline 15 January & 81-mm mortar & 3 & Detonation and sampling \\
\hline 16 January (morning) & $\begin{array}{l}\text { 81-mm mortar } \\
\text { 105-mm howitzer }\end{array}$ & $\begin{array}{l}2 \\
2\end{array}$ & $\begin{array}{l}\text { Detonation and sampling } \\
\text { Detonation and sampling }\end{array}$ \\
\hline 16 January (afternoon) & 105-mm howitzer & 5 & Detonation and delineation of plumes \\
\hline 17 January & 105-mm howitzer & $(5)^{\star}$ & Sampling of plumes \\
\hline
\end{tabular}

Prior to detonation, locations for the rounds were marked and sampled for background contamination. The rounds were set up by the troops under the supervision of the UXO technician to ensure uniformity of configuration. Following detonation, a GPS technician walked the outline of the plumes, demarcating the estimated residue area based on the observable soot. Sampling of the plumes then commenced using the methods briefly described below.

The Discrete Sampling Method (DSM) entails using a 0.45-m-wide Teflonlined snow shovel to collect several approximately $1-\mathrm{m}^{2}$-sized samples from the surface of the snow to a depth of about $2 \mathrm{~cm}$, plus whatever visible residues may remain in the sampled area. Each sample is placed in its own polyethylene bag for later analysis. The goal is to sample as much of the plume area as is practical, excluding the crater at the detonation point. This will vary between less than $1 \%$ of the area for large munitions to $80 \%$ for smaller ordnance, resulting in anywhere from five to 25 samples per plume. Plume size is heavily influenced by wind speed, which makes the area sampled difficult to generalize for a particular round. Sampling location is to be random and not influenced by plume coloration. A more thorough treatment of this subject can be found in Jenkins et al. (2002).

In addition to the collection of the DSM samples, three alternative sampling methods were tested. Adjacent sampling (Adjacents) entails taking a $0.04-\mathrm{m}^{2}$ 
sample adjacent to each DSM sample using a 20- $\times 20$-cm hand scoop and combining samples in a single bag for processing and analysis. The objective of this test was to investigate whether smaller samples composed of increments corresponding to DSM locations give results similar to those of DSM samples. This tests both the repeatability of the sampling methods and the validity of multipleincrement sampling.

For the medium-increment sampling method (MIS), increments are taken while walking evenly spaced (1- to 2-m) lanes within the plume. The goal is to collect about 40 systematic-random increments with a $20-\times 20$-cm hand scoop; these are then combined in a single bag. Systematic-random sampling is the collection of increments in a random location within a rough grid. The objective of MIS sampling is to quantify the plume residues by obtaining a single representative sample composed of increments collected in a systematic-random fashion while covering the entire plume without being influenced by soot deposition darkness or proximity to the detonation point and crater.

Large-increment sampling (LIS) provides more complete coverage of the plume through the collection of a large number of small increments. The goal is to collect approximately 100 random increments while covering the complete plume, including the crater. A $0.01-\mathrm{m}^{2}(10-\times 10-\mathrm{cm})$ hand scoop is used to collect the samples. A sample bag will hold one LIS. The objective of largeincrement sampling is the same as MIS sampling, with the aim of better plume representation through a more distributed sampling pattern that includes the detonation craters.

All samples and increments are taken to a depth of about $2 \mathrm{~cm}$. Visible residue remaining in the sampled area is removed with a small hand scoop and placed in the sample bag. The bags, $38-\times 76-\mathrm{cm}$ particle-free polyethylene bags, are sealed with a cable tie that also holds a label describing the sample. DSM samples are left at their sampling locations for later position measurement; the other samples are left near the plume for later transportation to the processing area.

The process of estimating explosives residues from surface snow samples is based on work outlined in Walsh and Ranney (1998), Jenkins et al. (2002), and Hewitt et al. (2003). Essentially, the snow samples are thawed, the filtrate separated from the soot fraction and concentrated using solid-phase extraction, explosives concentrations are determined for each fraction using chromatographic instrumentation, and the concentrations combined and extrapolated over the whole plume to determine residue masses. For the DSM studies, we looked at residues of RDX and HMX, a manufacturing contaminant of RDX. Table C-2 gives the mass estimates for each plume based on the sample type. 


\section{Application and Confirmation Tests}

Tests implementing the protocol chosen as a result of comparative tests were conducted 16-17 March at Eagle River Flats, north of the location of the January tests. The weather was much milder, with early-morning temperatures ranging from $-13^{\circ}$ to $-6^{\circ} \mathrm{C}$. Winds were variable, coming out of the south on the 16 th with no wind recorded during detonation on the 17th. This worked out well as the detonation line on the 16th was the northernmost line. A trace amount of snow fell prior to detonation of the rounds on the 16th, with no precipitation during the tests on the 17th. Scattered clouds minimized the effect of the much stronger sun, with some effect on the plumes after noon. However, most sampling was complete by that time. Table 3 outlines the test schedule as executed.

\begin{tabular}{|c|c|c|c|}
\hline \multicolumn{4}{|c|}{ Table 3. Test execution for protocol application tests. } \\
\hline Date & Munition & Quantity & Tasks \\
\hline 16 March & $155-\mathrm{mm}$ howitzer & 7 & Detonation and sampling \\
\hline 17 March & $155-\mathrm{mm}$ howitzer & 7 & Detonation and sampling \\
\hline
\end{tabular}

The sampling protocol chosen for further testing was the LIS. As described above, this method samples the complete plume, including the crater, using a 10$\times 10-\mathrm{cm}$ scoop and collecting around 100 increments. For every plume, at least two LISs were collected and other quality assurance (QA) procedures were implemented. The first set of rounds was filled with Comp-B, the same filler used for the protocol tests described above. The second set of rounds used TNT as the explosive filler. Both sets of rounds were detonated with a single demolition block charge of C4 (DODIC M023) as the donor charge. An M739 pointdetonating fuze (DODIC N340) was installed in each round. All rounds contained a supplementary TNT charge in the fuze well below the M739 fuze (see Appendix A). Figure 3 shows the setup common for all the rounds. All seven rounds for each test were detonated within a three-second window. No DSM samples were collected on either date.

\section{Quality Assurance}

Quality assurance (QA) was an important part of both series of tests. Field QA procedures were developed and implemented to verify that the data obtained using this sampling method are valid. Some of these procedures were carried over to the protocol application tests, with additional QA procedures conducted to further validate the new protocol. Table 4 outlines the QA tests conducted over the course of the study. 




Figure 3. Detonation setup for 155-mm implementation tests.

\begin{tabular}{|l|l|l|}
\hline \multicolumn{3}{|c|}{ Pable 4. Quality assurance procedures. } \\
\hline \multicolumn{1}{|c|}{ Procedure } & \multicolumn{1}{c|}{ Description } & \multicolumn{1}{c|}{ Objective } \\
\hline Subsurface sampling & $\begin{array}{l}\text { Samples are collected beneath } \\
\text { areas previously sampled. }\end{array}$ & $\begin{array}{l}\text { To determine whether the sampler is } \\
\text { collecting all residue from a location. }\end{array}$ \\
\hline $\begin{array}{l}\text { Duplicate and } \\
\text { triplicate sampling }\end{array}$ & $\begin{array}{l}\text { Sampling method is repeated within } \\
\text { a specific plume. }\end{array}$ & $\begin{array}{l}\text { To determine the repeatability of a } \\
\text { sampling method. }\end{array}$ \\
\hline Paired MIS sampling & $\begin{array}{l}\text { Two MIS samples in the same } \\
\text { plume consisting of adjacent } \\
\text { increments. }\end{array}$ & $\begin{array}{l}\text { To estimate the repeatability of multi- } \\
\text { increment sampling through close- } \\
\text { proximity replicate sampling. Examine } \\
\text { residues heterogeneity. }\end{array}$ \\
\hline $\begin{array}{l}\text { Radial sampling } \\
\text { within the plume }\end{array}$ & $\begin{array}{l}\text { The plume is divided into zones } \\
\text { radiating out from the detonation } \\
\text { point. LISs collected in each zone. }\end{array}$ & $\begin{array}{l}\text { To determine the influence of sampling } \\
\text { in proximity to the detonation point to the } \\
\text { overall estimated residue deposition. }\end{array}$ \\
\hline $\begin{array}{l}\text { Gradient (gray-scale) } \\
\text { sampling within the } \\
\text { plume }\end{array}$ & $\begin{array}{l}\text { The plume is divided into three } \\
\text { zones by the perceived density of } \\
\text { the residue soot. LISs are collected } \\
\text { in each zone. }\end{array}$ & $\begin{array}{l}\text { To determine the influence of sampling } \\
\text { bias toward darker areas. }\end{array}$ \\
\hline $\begin{array}{l}\text { Radial sampling } \\
\text { outside the plume }\end{array}$ & $\begin{array}{l}\text { Sampling outside the demarcated } \\
\text { plume and within concentric rings } \\
\text { centered on the detonation point. }\end{array}$ & $\begin{array}{l}\text { To determine whether the soot plume } \\
\text { correctly models the distribution of } \\
\text { explosives residues following a } \\
\text { detonation. }\end{array}$ \\
\hline $\begin{array}{l}\text { Annular sampling } \\
\text { outside the plume }\end{array}$ & $\begin{array}{l}\text { Sampling outside the demarcated } \\
\text { plume within a concentric ring } \\
\text { surrounding the plume or the edge } \\
\text { of another annular sampling area. }\end{array}$ & $\begin{array}{l}\text { To determine whether the demarcation } \\
\text { of the residues plume is correct. }\end{array}$ \\
\hline \multicolumn{2}{|c|}{}
\end{tabular}


Subsurface sampling was conducted on DSM samples in January and on one of each paired MIS samples in March. In January, the subsurface sample size matched that of the surface sample, and both samples were collected in the same manner. In March, the subsurface samples were smaller than the surface sample to avoid the possibility of contamination along the edge of the subsample.

Duplicate and triplicate sampling was conducted on all other types of samples during tests both months. Paired MIS samples in March were collected with a $0.023-\mathrm{m}^{2}(15-\times 15-\mathrm{cm})$ hand scoop adjacent to each other and deposited in separate bags. Radial sampling within the plume entailed dividing the plume into three zones, each concentric from the detonation point (0- to 10-m radius, 10 - to $20-\mathrm{m}$ radius, and greater-than-20-m radius). A LIS was then taken within each zone. The gradient sampling within the plume entailed dividing the plume into three zones based on the perceived density of the deposited soot. The denser the soot, the darker the area of the plume. A LIS was taken from each zone. Sampling outside the plume was done using two procedures. In one, samples were taken within a band or annulus outside the plume. Up to two concentric bands (0-3 m and 3-6 m) were sampled using the LIS method (Fig. 4). The other procedure entailed sampling outside the plume within a fixed band radiating from the detonation point (0-10 $\mathrm{m}$ and 10-20 m). Appendix B lists the QA tests conducted for each detonation.

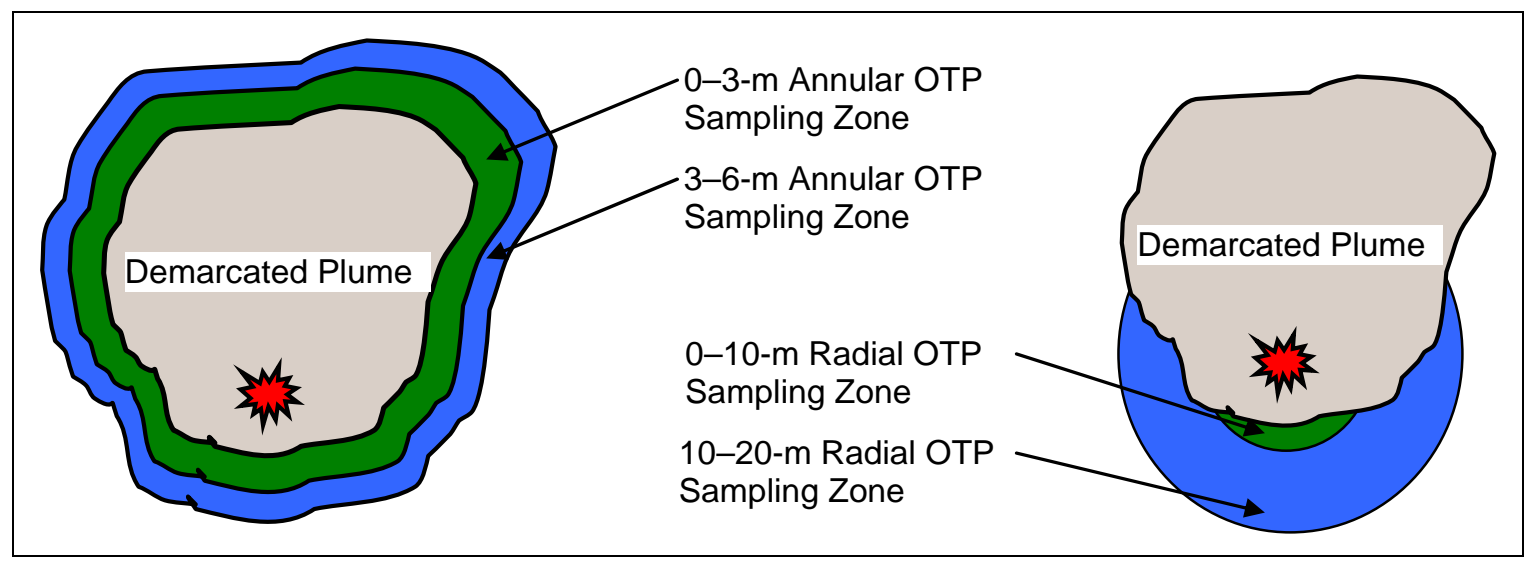

a. (Left) Annular zones.

b. (Right) Radial zones.

Figure 4. Sampling diagrams for outside-the-plume (OTP) sampling. 


\section{$4 \quad$ RESULTS AND DISCUSSION}

This section will be divided into three parts: An examination of the DSM protocol, comparison with the other protocols tested in January, and the results of the implementation testing of the new protocol in March. QA methods will be discussed throughout as applicable.

\section{Protocol Tests-The Discrete Sampling Method}

Protocol testing on the DSM was conducted on 14 rounds. Seven 81-mm plumes and seven 105-mm plumes were sampled. A total of 123 large discrete and five multi-increment samples was taken of the 81 -mm detonations, and 128 large discrete and three multi-increment samples were collected from the 105$\mathrm{mm}$ detonations. Detonation crater samples are considered separately. In general, the portion of the total plume area sampled was small, less than $4 \%$ ranging down to less than $1 \%$. All surface and subsurface discrete samples were $1 \mathrm{~m}^{2}$ in size. The OTP sampling was done with $10-\mathrm{cm}$ or $20-\mathrm{cm}$ hand scoops and was composed of 40 to 120 increments. Appendix C, Table C-1, gives the DSM sampling statistics for the plumes and OTP bands. Table 5 summarizes these data.

\begin{tabular}{|l|c|}
\hline \multicolumn{2}{|c|}{ Table 5. Detonation plume data for DSM tests. } \\
\hline \multicolumn{1}{|c|}{ Parameter } & Statistics \\
\hline \multicolumn{1}{|c|}{ 81-mm plumes } & $\mathbf{n = 7}$ \\
\hline Number of samples: Discretes (total/average) & $22 / 2$ \\
Subsurface (Total/\# of plumes) & 4 \\
Outside the plume* & $637 \mathrm{~m}^{2}-1506 \mathrm{~m}^{2}$ \\
\hline Range of plume areas & $820 \mathrm{~m}^{2}$ \\
\hline Average plume area & $310 \mathrm{~m}^{2}-490 \mathrm{~m}^{2}$ \\
\hline Range of OTP areas & $410 \mathrm{~m}^{2}$ \\
\hline Average of OTP areas & $11 \mathrm{~m}^{2}-34 \mathrm{~m}^{2} / 0.73 \%-2.2 \%$ \\
\hline Range of sampled areas: Plumes (Area/\% of plume) & $0.80 \mathrm{~m}^{2}-1.6 \mathrm{~m}^{2} / 0.21 \%-0.46 \%$ \\
OTPs (Area/\% of OTP area) & $14 \mathrm{~m}^{2} / 1.8 \%$ \\
\hline Average of sampled areas: Plumes (Area/\% of plume) & $1.3 \mathrm{~m}^{2} / 0.32 \%$ \\
OTPs (Area/\% of OTP area) & $50 \%$ \\
\hline OTP area to plume area & \\
\hline
\end{tabular}




\begin{tabular}{|l|c|}
\hline \multicolumn{2}{|c|}{ Table 5 (cont'd). } \\
\hline \multicolumn{1}{|c|}{ Parameter } & Statistics \\
\hline \multicolumn{1}{|c|}{ 105m plumes } & $\mathbf{n}=\mathbf{7}$ \\
\hline $\begin{array}{l}\text { Number of samples: Discretes (Total/Average) } \\
\text { Subsurface (Total/\# of plumes) } \\
\text { Outside the plume }\end{array}$ & $113 / 16$ \\
\hline Range of plume areas & 3 \\
\hline Average plume area & $440 \mathrm{~m}^{2}-1300 \mathrm{~m}^{2}$ \\
\hline Range of OTP areas & $860 \mathrm{~m}^{2}$ \\
\hline Average of OTP areas & $400 \mathrm{~m}^{2}-490 \mathrm{~m}^{2}$ \\
\hline Range of sampled areas: Plumes (area/\% of plume) & $450 \mathrm{~m}^{2}$ \\
OTPs (Area/\% of OTP area) & $15 \mathrm{~m}^{2}-18 \mathrm{~m}^{2} / 1.2 \%-3.4 \%$ \\
\hline Average of sampled areas: Plumes (area/\% of plume) & $0.66 \mathrm{~m}^{2}-0.82 \mathrm{~m}^{2} / 0.14 \%-0.18 \%$ \\
OTPs (Area/\% of OTP area) & $16 \mathrm{~m}^{2} / 1.9 \%$ \\
\hline OTP area to plume area & $0.71 \mathrm{~m}^{2} / 0.16 \%$ \\
\hline * Data for the one 0- to 10-m radius OTP test are not included: there were no detectable residues in this \\
test.
\end{tabular}

One of the objectives of the DSM protocol is to collect enough samples to derive a valid representation of the plume. However, the average area of the plumes is quite large $\left(840 \mathrm{~m}^{2}\right)$. To sample a significant portion of the plume, around $10 \%, 50$ to 150 discrete samples would have to have been collected. Even half that number is impractical. The $10 \%$ target was not derived in a scientific manner but was set as a goal when the DSM protocol was being developed. However, ongoing work by several researchers at CRREL indicates that to adequately represent a substance heterogeneously deposited over a given area, at least 30 samples (or increments) need to be obtained. The total number is a function of the increment size and sampling area. Taking 10 to 20 DSM samples, in the $1 \%-3 \%$ range, is more practical. Taking fewer samples (or increments) makes it more difficult to obtain representative samples, which will be demonstrated in the section on the distribution of samples that follows.

Prior to sampling, two of the 81-mm plumes were checked from an 8-m-high tower after delineation by the GPS technician to qualitatively determine whether the complete plume was being demarcated. Both plumes looked fully enveloped, and OTPs were done on both to verify this observation.

Using estimates of the residues masses, we looked for sources of sampling error for the DSM tests. The two most obvious places are beneath the areas sampled and outside the demarcated plumes. Residues in these areas will result in an underestimation of the unreacted mass of explosives. Other sources of error 
are the possible biasing of the sampling toward the detonation point and oversampling the darker areas of the plume (sample location). These will likely have the opposite effect, resulting in an overestimation of the residue mass. Finally, the contribution and sampling procedure for the craters will be examined.

\section{Subsurface residues}

Subsurface samples were taken from three plumes. All three subsurface samples were DSM-type samples $\left(1 \mathrm{~m}^{2} \times 2 \mathrm{~cm}\right.$ deep $)$ and contained residues. The results are given in Tables 6 and C-2. The subsurface residues were higher than we anticipated and constitute what appears to be a significant source of error $(\approx 10 \%)$. Collection conditions may have been the cause of some of the error. The difficulty of working in the extremely low temperatures during the $81-\mathrm{mm}$ tests $\left(\approx-35^{\circ} \mathrm{C}\right)$ likely contributed to some sampling error while collecting the discretes. The subsample for the $105-\mathrm{mm}$ round was taken on the final day of sampling, when temperatures were more moderate $\left(-10^{\circ} \mathrm{C}\right)$ and more time was available for sampling. However, more work needs to be done to get a better indication of the magnitude of the error. Some of this was done as part of the pre-existing sampling plan for the protocol tests and some was built into the application tests to take place in March. From this test it is obvious that care must be taken to ensure that proper sampling depth is achieved and that any residues beneath the sampled area are collected during the sampling process.

\begin{tabular}{|c|c|c|c|c|}
\hline \multirow[b]{2}{*}{ Plume } & \multicolumn{2}{|c|}{ Residues recovered $(\mathrm{mg})$} & \multicolumn{2}{|c|}{$\%$ of total mass* } \\
\hline & HMX & RDX & HMX & RDX \\
\hline $81-1$ & 1.4 & 3.7 & $11 \%$ & $16 \%$ \\
\hline $81-5$ & 1.0 & 1.4 & $12 \%$ & $11 \%$ \\
\hline $105-6$ & 0.68 & 1.6 & $5.8 \%$ & $6.0 \%$ \\
\hline Average & - & - & $9.6 \%$ & $11 \%$ \\
\hline
\end{tabular}

\section{Residues outside the demarcated plume}

The results for the outside-the-plume samples indicate that plume demarcation is adequate. Two types of tests were performed, sampling a 3-m-wide concentric zone outside the plume and sampling within a fixed distance from the detonation point outside the plume. The majority of tests were of the concentric OTP configuration, with one radial test to determine whether our strategy of 
sampling the visible plume (wind dispersion) rather than in concentric circles from the detonation point (radial dispersion) is valid. The results are given in Table 7. Residues averaged less than 1\% of DSM values for HMX and less than $2 \%$ of DSM values for RDX. The one test done using the radial OTP strategy came up blank. These tests indicate that we are delineating the plume correctly and that the strategy of sampling within the visible plume for residues is likely sufficient. More data on the radial sampling outside the plume are needed to reinforce the second conclusion, and additional concentric data are needed to confirm the delineation strategy. It is important to note that the OTP samples were multi-increment and not discrete samples.

\begin{tabular}{|c|c|c|c|c|c|}
\hline \multirow[b]{2}{*}{ Plume } & \multirow[b]{2}{*}{ Area sampled } & \multicolumn{2}{|c|}{ Residues recovered (mg) } & \multicolumn{2}{|c|}{$\%$ of total mass* } \\
\hline & & HMX & RDX & HMX & RDX \\
\hline $81-1$ & 0 - to 3-m annulus & 0.18 & ND & $1.6 \%$ & $0 \%$ \\
\hline $81-2$ & 0 - to 3-m annulus & ND & ND & $0 \%$ & $0 \%$ \\
\hline $81-3$ & 0 - to 3-m annulus & ND & ND & $0 \%$ & $0 \%$ \\
\hline \multirow[t]{2}{*}{$81-5$} & 0- to 3-m annulus & ND & 0.36 & $0 \%$ & $1.1 \%$ \\
\hline & 0 - to $10-\mathrm{m}$ radius & ND & ND & $0 \%$ & $0 \%$ \\
\hline $105-3$ & 0- to 3-m annulus & 0.15 & 2.2 & $2.1 \%$ & $6.2 \%$ \\
\hline $105-5$ & 0- to 3-m annulus & 0.25 & 2.4 & $2.2 \%$ & $2.8 \%$ \\
\hline $105-7$ & 0- to 3-m annulus & ND & 0.43 & $0 \%$ & $2.5 \%$ \\
\hline Average & & & & $0.70 \%$ & $1.8 \%$ \\
\hline \multicolumn{6}{|c|}{ ND = Not detected } \\
\hline
\end{tabular}

\section{Sample distribution}

As noted above, we looked at the DSM data in relation to the detonation point and the perceived darkness of areas within the plume to try to determine whether these factors influence the samplers' decisions as to where to sample. After completion of the DSM sampling, concentric rings were walked around the detonation points (10-m and 20-m radius) for Plumes 81-5, 105-3, and 105-7. Dark- and medium-density gray zones were also demarcated on Plume 105-4. These boundaries were entered in the GPS database, as were all the DSM locations for these and the other plumes. The 10- and 20-m radial zone boundaries were also determined for the remaining plumes and added to the GPS data to provide a wider statistical base for bias evaluation. The distribution of samples 
points and the residues in these areas were then examined. Data for the distribution of DSM samples are given in Table C-3. Summary results are in Table 8.

\begin{tabular}{|c|c|c|c|c|c|c|}
\hline \multicolumn{7}{|c|}{ Table 8. Detonation proximity bias in DSM sample location. } \\
\hline Round & Zone & Area $\left.\mathbf{( m}^{\mathbf{2}}\right)^{*}$ & \# of samples & \% samples & \% area & Samples/area $^{\dagger}$ \\
\hline \multirow{2}{*}{$\begin{array}{c}81-m m \\
(\mathrm{n}=8)\end{array}$} & $0-10 \mathrm{~m}$ & 178 & 5.6 & $44 \%$ & $24 \%$ & 2.0 \\
\cline { 2 - 7 } & $10-20 \mathrm{~m}$ & 261 & 5.0 & $41 \%$ & $33 \%$ & 1.3 \\
\cline { 2 - 7 } & $>20 \mathrm{~m}$ & 381 & 2.0 & $15 \%$ & $44 \%$ & 0.3 \\
\hline \multirow{2}{*}{$\begin{array}{c}105-\mathrm{mm} \\
(\mathrm{n}=3)\end{array}$} & $0-10 \mathrm{~m}$ & 267 & 7 & $42 \%$ & $30 \%$ & 1.4 \\
\cline { 2 - 7 } & $10-20 \mathrm{~m}$ & 387 & 6.3 & $39 \%$ & $44 \%$ & 0.9 \\
\cline { 2 - 7 } & $>20 \mathrm{~m}$ & 244 & 3.3 & $19 \%$ & $26 \%$ & 0.7 \\
\hline \multirow{2}{*}{$\begin{array}{l}\text { * Average values for plumes. } \\
+\end{array}$} \\
Ratio of the \% samples to \% area.
\end{tabular}

Sample distribution for these tests is very interesting. The area closest to the craters was sampled on average twice as frequently for the $105-\mathrm{mm}$ tests as compared to the area beyond $20 \mathrm{~m}$ from the detonation point, and for the $81-\mathrm{mm}$ tests, the factor is over six times. Sampling in the middle zone, 10 to $20 \mathrm{~m}$ out, is more representative, but is still skewed for the $81-\mathrm{mm}$ tests. The distribution improved greatly between the $81-\mathrm{mm}$ tests and the $105-\mathrm{mm}$ tests, but the density of samples near the detonation point was still high. Even though an increasing effort was made to sample in a more distributed manner, a bias still remained.

There are a couple of confounding factors that may be influencing this bias. The plume tends to be darkest in close proximity to the detonation point, and a bias toward sampling the darkest areas may be reflected in a proximity bias. Samplers also tend to start sampling near the crater, as that is where the access path leads. Finally, it is difficult when sampling to keep the size and shape of the plumes in perspective. This leads to a concentration on sampling with respect to the last sample point and not with respect to the plume as a whole.

Another way of looking at the proximity sampling bias is to compare the results for a plume assuming no sampling bias with the results corrected for the sampling patterns found from these tests. To do this, the DSM samples within specific zones of the plumes were mathematically composited and the residue masses estimated for those zones. These were then combined, correcting (weighting) for differences in zonal areas, and compared to the masses derived for the no-bias assumption. Data for these comparisons are given in Table C-4 and the results summarized in Table 9. The values given for HMX and RDX are the percent differences between the unweighted (no-bias assumption: $\mathrm{M}_{\mathrm{u}}$ ) values for the 
DSMs and the values taking the oversampling in proximity to the craters into account $\left(\mathrm{M}_{\mathrm{w}}\right)$.

$$
\operatorname{Bias}=\left(M_{u}-M_{w}\right) / M_{w}
$$

A positive percentage indicates the possible overestimation of residues by the standard DSM method.

\begin{tabular}{|c|c|c|}
\hline \multicolumn{3}{|c|}{ Table 9. Detonation proximity bias (unweighted vs. } \\
weighted) in DSM residues estimates. \\
\hline Plume & HMX & RDX \\
\hline $\begin{array}{c}81-\mathrm{mm} \\
(\mathrm{n}=8)\end{array}$ & $46 \%$ & $31 \%$ \\
\hline $\begin{array}{c}105-\mathrm{mm} \\
(\mathrm{n}=3)\end{array}$ & $27 \%$ & $24 \%$ \\
\hline $\begin{array}{c}\text { Overall bias } \\
(\mathrm{n}=11)\end{array}$ & $38 \%$ & $28 \%$ \\
\hline
\end{tabular}

The results of this analysis indicate a proximity bias. The calculated plume residual masses using composited DSM samples are more than $25 \%$ greater than when sample location is taken into account and the samples are weighted with respect to area. Again, the results for the 105-mm sampling indicate a better distribution of samples, reflecting the greater effort to obtain more representative samples later in the process. The results show that plume residues masses will be overestimated based on sample location bias with respect to the detonation point.

Data for the gray-scale test are more divergent than for the concentric data. Although we have only one test examining the effect of soot density in the plume on sampling bias, it is worth noting. Table 10 contains the data and analysis for this condition. Bias is measured as the ratio represented in Equation 1.

\begin{tabular}{|c|c|c|}
\hline Condition & HMX (mg) & RDX (mg) \\
\hline Weighted & 4.5 & 10 \\
\hline Standard DSM & 6.6 & 15 \\
\hline Bias & $47 \%$ & $50 \%$ \\
\hline
\end{tabular}


The soot density biases of $47 \%$ and $50 \%$ for HMX and RDX are quite different from the concentricity data, especially when compared to the later (105$\mathrm{mm}$ ) results. This applies to the results specific to the plume as well, Plume 1054. A comparison of the collection point zone oversampling (Table C-3) tends to reinforce this observation, as the soot density bias is much larger than the proximity bias (a factor of 2.2 vs. 1.3 for the dark gray area vs. the $<10-\mathrm{m}$ zone and a factor of 1.6 vs. 0.94 for the medium gray area vs. the 10- to $20-\mathrm{m}$ zone). Again, a conscious effort was made not to bias sampling. Further data for the proximity and gray-scale bias hypotheses are needed if DSM sampling is to continue to be used.



Figure 5. Replicate discrete sampling on Plume 81-3.

We obtained duplicate DSM samples of only one plume during these tests, Plume 81-3. The samples were taken by two different sampling teams, the second set being obtained after the first set was done. Figure 5 shows the sample locations for both sets. It is immediately obvious that the sample distributions are quite different. For the (a) set of samples, the most proximate area $(0-10 \mathrm{~m})$ is oversampled by about $50 \%$. For the (b) set of samples, this number rises to $120 \%$. The central area of the plume $(10-20 \mathrm{~m})$ is fairly well represented $(100 \%$ and $120 \%$ representation), whereas the difference again widens for the area beyond $20 \mathrm{~m}: 74 \%$ and $26 \%$, respectively. If the area beyond the $20-\mathrm{m}$ line is divided by a $30-\mathrm{m}$ line, the (b) samples have no representation beyond that line. 
The second set of samples (b) is more concentrated near the detonation point (see also Table C-3).

Reverting back to the three-zone division of the plume, the overall residues were calculated for the plume (Table C-4). A comparison between the two samples for Plume 81-3 is given in Table 11. In this table, $U_{a}$ and $U_{b}$ are unweighted values and $\mathrm{W}_{\mathrm{a}}$ and $\mathrm{W}_{\mathrm{b}}$ are weighted residue mass values of DSM samples. It is evident that there is a difference between the two samples, with the sample collected closest to the detonation point (b) indicating more contamination than the more evenly distributed sample (a). The attribution of the greater residues for (b) to proximity to the detonation point may be misleading, as the majority of the difference between the samples comes from the poorly sampled zone beyond the $20-\mathrm{m}$ radius. Thus, the difference between the samples may be attributable more to sampling sooty areas than sampling near the detonation point. Without knowing the outline of the soot gradients and having a better grasp of the residue load in the plume, a more precise determination of any sampling bias cannot be made. Although the results are for only one set of data, the agreement between the two sample sets is surprisingly close, indicating a robustness for the DSM sampling protocol not thought to exist.

\begin{tabular}{|c|c|c|c|}
\hline Comparison & Relationship & HMX & RDX \\
\hline Raw data: a & No weighting for zones & $1.1 \mathrm{mg}$ & $8.1 \mathrm{mg}$ \\
\hline Raw data: $b$ & No weighting for zones & $1.5 \mathrm{mg}$ & $10 \mathrm{mg}$ \\
\hline Unweighted bias: $\mathrm{b}$ to $\mathrm{a}$ & $\left(U_{b}-U_{a}\right) / U_{a}$ & $+36 \%$ & $+24 \%$ \\
\hline Weighted bias: $\mathrm{b}$ to $\mathrm{a}$ & $\left(W_{b}-W_{a}\right) / W_{a}$ & $+21 \%$ & $+162 \%$ \\
\hline 0 - to $10-\mathrm{m}$ zone: $\mathrm{b}$ to $\mathrm{a}$ & $\left(\cup_{b}-U_{a}\right) / \cup_{a}$ & $+44 \%$ & $-31 \%$ \\
\hline 10- to $20-m$ zone: $\mathrm{b}$ to $\mathrm{a}$ & $\left(U_{b}-U_{a}\right) / U_{a}$ & $-66 \%$ & $-57 \%$ \\
\hline$>20-\mathrm{m}$ zone: $\mathrm{b}$ to $\mathrm{a}$ & $\left(U_{b}-U_{a}\right) / U_{a}$ & $+460 \%$ & $+1100 \%$ \\
\hline
\end{tabular}

In summary, there is bias evident in the location of samples within a detonation plume. The source of this bias may be from one or all of the following factors: tendency to sample closest to the detonation point, tendency to start sampling near the detonation point, tendency to sample within the darkest areas of the plumes, and a failure to take the full plume into consideration when choosing sample locations. The overall effect of these biases taken individually and as a group on the residues estimates will need to be determined by comparison with data that are more representative of the plume. 


\section{Craters}

Missing from the above analyses are the craters. Hewitt et al. (2003) indicate that the craters (detonation points) typically do not significantly alter the overall residue quantities for detonated rounds. In live-fire tests conducted at Eagle River Flats in March 2002, fourteen 81-mm mortar rounds and thirteen 105-mm howitzer rounds were fired onto the snow-covered ice and sampled using the discrete sampling method. The craters were sampled separately. The results from this test showed a measurable contribution of less than $2 \%$ in the RDX residue quantity for only one of the 27 detonation points examined. The remainder were below the detection limit. Although the detonation points can have a higher residue concentration than the rest of the plume, their area is very small $(<1 \%)$ compared to the remainder of the plume. Thus, although residues concentrations may be comparatively high within the craters, their contribution to the overall residue estimate is not significant in most cases.

We evaluated the inclusion of the craters as part of the protocol tests. Craters have always been sampled using incremental sampling. Generally, 5\% to $10 \%$ of the crater is sampled for analysis. Part of our study was to look at the repeatability of the sampling technique for craters and whether sampling the various parts of the crater separately results in different residue deposition values. Six of the seven $81-\mathrm{mm}$ detonation craters were sampled, as were six of the seven 105$\mathrm{mm}$ craters. During sampling of the craters, the area was undergoing sub-ice interlayer infiltration by water, resulting in water seepage into the craters, especially in the center pits below the round locations. Not all components of each crater were available for sampling.

The crater centers are quite small in relationship to the overall crater and, based on past data, generally contribute little to the residues load in the crater $(<10 \%)$. We were able to obtain only one good center sample that amounted to $6 \%$ of the crater residues. The centers tend to be very difficult to sample (even without the presence of water) as they are full of debris, in this case fractured ice in the form of small chips as well as frag or, in the case of live-fired rounds, mortar tail assemblies. We thus concentrated on two areas within the crater: the annulus, the area generally clear of snow between the edge of the detonation center and the berm; and the berm, the raised rim of snow surrounding the detonation point and outlining the crater. Corresponding berm and annulus samples were obtained for eight of the 14 craters. Table 12 contains the data for these crater components. 


\begin{tabular}{|c|c|c|c|}
\hline \multicolumn{5}{|c|}{ Table 12. Data for crater components (RDX). } \\
\hline Detonation point & Annulus $(\mathbf{m g})$ & Berm $(\mathbf{m g})$ & Difference $(\mathbf{m g})$ \\
\hline $81-1$ & 0.033 & 0.042 & -0.009 \\
\hline $81-3$ & 0.069 & 0.14 & -0.072 \\
\hline $81-7$ & 0.62 & 0.24 & 0.385 \\
\hline $105-1$ & 0.96 & 0.91 & 0.042 \\
\hline $105-2$ & 0.76 & 2.9 & -2.1 \\
\hline $105-3$ & 0.14 & 1.0 & -0.88 \\
\hline $105-4$ & 0.75 & 0.67 & 0.077 \\
\hline $105-7$ & 2.0 & 1.2 & 0.76 \\
\hline
\end{tabular}

Using the data from Table 12, a paired t-test can be used to test the deposition amounts of the RDX residues for the two crater components to determine whether they differ significantly. From Natrella (1963), the statistics for this test are as follows:

Significance level: 0.05

Average difference: -0.23

Statistical deviation of differences: 0.90

Sample size: 8

Degrees of freedom: 7

$\mathrm{t}_{\text {Calc }}: 0.753$

$\mathrm{t}_{(0.975)}: 2.365$

In our case, $\mathrm{t}_{\text {Calc }}$ is much less than $\mathrm{t}_{(0.975)}$. This indicates that there is no significant difference in residues between the crater berm and annulus. Thus, no extra care must be exercised when sampling the crater, and if the annulus is inaccessible, sampling the berm will sufficiently characterize the crater as a whole.

We took duplicate annulus and berm samples at three of the craters. For the RDX residues, the relative percent difference between each of the two measurements was around $20 \%$. Repeatability increased with the number of increments, being best with $50-100$ increments ( $0 \%$ and $7 \%$ difference), increasing to $44 \%$ and $56 \%$ for the sample with less 40 increments. The third set, taken with 40-60 increments, fell in between with differences of $14 \%$ and $16 \%$. The average underreporting of the total residue mass in the plumes due to ignoring the crater is $6 \%$ over the 12 samples taken during these tests. 
In summary, sampling the crater is not critical in obtaining the overall residues quantities for a plume, although it will add to the accuracy of the results. Taking many increments increased the repeatability of the sample measurements, thus a large-increment sample should give a more accurate representation of the crater if required. The distribution of these increments within the crater is not critical to the repeatability of the results but distributed (representative) sampling is good practice and should be applied.

\section{Protocol Tests-Alternative Sampling Methods}

Examining the feasibility of replacing DSM sampling with a more efficient sampling method was the primary goals of these tests. Processing of the many large DSM samples is time-consuming and expensive. For large plumes, it is also not very practical. Therefore, we sought to examine the feasibility of using multiple-increment sampling for characterizing the plume.

Multi-increment sampling is already used as part of the DSM method. Craters are sampled using many small increments, and the large plume samples are mathematically averaged over the complete plume to derive the total residues. The ability to characterize a plume with a single sample would greatly increase efficiency and allow replicate sampling and field quality assurance procedures to be conducted.

\section{Adjacent sampling}

To determine whether multiple-increment sampling can be used in place of the DSM, we collected 20- $\times 20-\times 2$-cm-deep increments adjacent to each DSM sample location. These increments were collected in a single bag in the field and processed in the lab as a single sample. A total of 19 multiple-increment adjacent samples was taken in the 14 plumes over the course of the protocol tests (Table D-1). The results of the adjacent samples were compared to the averaged DSMs to determine the validity of characterizing the plume using smaller samples distributed as with the DSM samples. Table 13 compares these values with those of the averaged DSMs.

Looking first at the proximity of the total residue estimates for the two sampling methods, agreement between the two methods is generally very good. The values are within a factor of two for most of the tests. Averaging the data for all the tests gives a result of $17 \mathrm{mg}$ HMX and $82 \mathrm{mg}$ RDX. The results for the adjacent samples average higher than for the DSMs for both constituents. This indicates that more residues were recovered during the adjacent sampling procedure than with the DSM procedure. This result was predicted because of the 
ease of obtaining a sample with the small hand scoop over the use of the large shovel with the DSM sample. This results in less spillage during sampling and better penetration into the snow with the sampling tool.

\begin{tabular}{|c|c|c|c|c|c|c|c|}
\hline \multirow[b]{2}{*}{ Plume \# } & \multirow[b]{2}{*}{ Method } & \multicolumn{2}{|c|}{ Mass estimates $(\mathrm{mg})$} & \multicolumn{2}{|c|}{ Mass differences* $(\mathrm{mg})$} & \multicolumn{2}{|c|}{ Relative \% differences } \\
\hline & & HMX & RDX & HMX & RDX & HMX & RDX \\
\hline \multirow{3}{*}{$81-1$} & Adjacent & 15 & 23 & & & & \\
\hline & Adjacent & 6.8 & 14 & & & & \\
\hline & DSM & 11 & 20 & -0.1 & -1.5 & $0.91 \%$ & $7.8 \%$ \\
\hline \multirow{2}{*}{$81-2$} & Adjacent & 9.4 & 4.9 & & & & \\
\hline & DSM & 5.6 & 7.2 & 3.8 & -2.3 & $51 \%$ & $38 \%$ \\
\hline \multirow{4}{*}{$81-3$} & Adjacent & 1.8 & 7.6 & & & & \\
\hline & DSM & 1.1 & 8.1 & 0.7 & -0.5 & $48 \%$ & $6.4 \%$ \\
\hline & Adjacent & 2.2 & 16 & & & & \\
\hline & DSM & 1.5 & 10 & 0.7 & 6.0 & $38 \%$ & $46 \%$ \\
\hline \multirow{3}{*}{$81-4$} & Adjacent & 20 & 640 & & & & \\
\hline & Adjacent & 97 & 720 & & & & \\
\hline & DSM & 57 & 470 & 1.5 & 210 & $2.6 \%$ & $37 \%$ \\
\hline \multirow{2}{*}{$81-5$} & Adjacent & 10 & 45 & & & & \\
\hline & DSM & 7.3 & 31 & 2.7 & 14 & $31 \%$ & $37 \%$ \\
\hline \multirow{2}{*}{$81-6$} & Adjacent & 67 & 280 & & & & \\
\hline & DSM & 55 & 220 & 12 & 60 & $20 \%$ & $24 \%$ \\
\hline \multirow{2}{*}{$81-7$} & Adjacent & 45 & 130 & & & & \\
\hline & DSM & 31 & 92 & 14 & 38 & $37 \%$ & $34 \%$ \\
\hline \multirow{2}{*}{$105-1$} & Adjacent & 6.1 & 11 & & & & \\
\hline & DSM & 2.8 & 13 & 3.3 & -2.0 & $74 \%$ & $17 \%$ \\
\hline \multirow{2}{*}{$105-2$} & Adjacent & 6.6 & 14 & & & & \\
\hline & DSM & 5.0 & 18 & 1.6 & -4.0 & $28 \%$ & $25 \%$ \\
\hline \multirow{2}{*}{$105-3$} & Adjacent & 9.6 & 17 & & & & \\
\hline & DSM & 6.9 & 33 & 2.7 & -16 & $33 \%$ & $32 \%$ \\
\hline \multirow{2}{*}{$105-4$} & Adjacent & 8.5 & 18 & & & & \\
\hline & DSM & 6.6 & 15 & 1.9 & 3.0 & $25 \%$ & $18 \%$ \\
\hline \multirow{3}{*}{$105-5$} & Adjacent & 29 & 180 & & & & \\
\hline & Adjacent & 24 & 54 & & & & \\
\hline & DSM & 11 & 82 & 15.5 & 35 & $83 \%$ & $35 \%$ \\
\hline \multirow{2}{*}{$105-6$} & Adjacent & 17 & 32 & & & & \\
\hline & DSM & 11 & 25 & 6.0 & 7.0 & $43 \%$ & $24 \%$ \\
\hline
\end{tabular}




\begin{tabular}{|c|c|c|c|c|c|c|c|}
\hline \multicolumn{8}{|c|}{ Table 13 (cont'd). Comparison of DSM and adjacent sampling. } \\
\hline \multirow[b]{2}{*}{ Plume \# } & \multirow[b]{2}{*}{ Method } & \multicolumn{2}{|c|}{ Mass estimates $(\mathrm{mg})$} & \multicolumn{2}{|c|}{ Mass differences* $(\mathrm{mg})$} & \multicolumn{2}{|c|}{ Relative \% differences } \\
\hline & & HMX & RDX & HMX & RDX & HMX & RDX \\
\hline \multirow{3}{*}{$105-7$} & Adjacent & 10 & 23 & & & & \\
\hline & Adjacent & 8.5 & 12 & & & & \\
\hline & DSM & 5.3 & 17 & 4.0 & 0.5 & $55 \%$ & $3 \%$ \\
\hline \multirow{3}{*}{ Average } & Adjacent & $19^{\star}$ & $94^{*}$ & 5.6 & $22^{\dagger}$ & & \\
\hline & DSM & 15 & 71 & & & & \\
\hline & $\mathrm{RPD}^{* *}$ & $24 \% *$ & $28 \% *$ & & & & \\
\hline \multicolumn{8}{|c|}{$\begin{array}{l}\text { * Mass differences are Adjacents - DSM: Adjacent duplicates averaged for these values. } \\
\text { + } 7.9 \mathrm{mg} \text { difference without 81-4 }\end{array}$} \\
\hline
\end{tabular}

All adjacent increments were taken next to the DSM samples, but replicate samples were not taken adjacent to each other. Relative percent differences (RPDs) in values obtained from replicate adjacent samples range from 12 to $130 \%$, with an average RPD of $60 \%$. The distance between the replicate increments likely accounts for some of the difference between the values, indicating that for small-increment samples $(i<30)$, each increment becomes more important and the sampling location can be critical. A test of this hypothesis was planned for the implementation tests (paired MIS samples with the same size scoop) in March.

The results of the adjacent sampling test indicate that DSM sampling can be replicated by multi-increment sampling. This is a significant finding as the single multi-increment sample has replaced 18 or more DSM samples, making it easier to obtain and process duplicate or triplicate samples for quality assurance. The data indicate somewhat higher residues values on average using the incremental sampling method, which may be due to the ability to obtain better samples with the smaller sampling tool. The other bias factors associated with DSM sampling remained with this exercise, including obtaining enough samples, or in this case increments, to adequately represent the plume residues in a repeatable manner. Craters were not sampled with either test.

An interesting anomaly appears in the data for Table 13 that gives an indication of the difficulties that can be encountered during blow-in-place characterization tests. The data for RDX for two of the five plumes are high when compared to those in the remaining three. Also, the ratio of RDX to HMX differs, especially for Plume 105-5. This may be indicative of less efficient detonation of the unconfined block of $\mathrm{C} 4$, used as the donor charge. The $\mathrm{C} 4$ block is $91 \%$ RDX. Separate tests done in conjunction with the 155-mm BIP 
tests indicate that following the proper detonation of an undeformed block of $\mathrm{C} 4$, the ratio of RDX to HMX residues is between 2:1 and 3:1. The donor charge efficiency and its influence on the residues plume is difficult to determine.

\section{Medium-increment samples}

We next tested full-plume incremental sampling that will allow the characterization of a plume with a single multi-increment sample. Previous work by M.E. Walsh et al. (2005) indicated that a minimum of 40 samples is required to accurately characterize a site. The standard sample bag we use for the collection of snow samples will hold 40 samples taken with a 20 -cm-square scoop at a depth of $2 \mathrm{~cm}$, so this tool was used.



The relative percent differences between the MIS and DSM sampling methods for 13 plumes are shown in Table 14. The MIS samples generally 
had lower concentrations of residues. However, the average values for the MIS samples are very close overall to those of the DSMs. The lower values were expected, as the MIS increments are more spatially representative of the complete plume. This results in a greater percentage of the sample being collected in areas away from the detonation point and less of a tendency to sample where the plume is darkest. It is interesting to note that as the DSM sampling became more spatially representative of the plume area (105-mm data), the differences between the sampling methods became smaller and more consistent.

For five of the plumes, we took multiple MIS samples (Table 15). Three triplicate and two duplicate MIS samples were collected over five plumes. Repeatability was good, even though many of these data are near the detection limits for the analytical method. The maximum difference from average for the sample groups is $41 \%$ for HMX and $53 \%$ for RDX. Data for these tests are in Table D-2.

Overall agreement of MIS data with the DSM data is surprisingly close, with the expected lower MIS residue estimates resulting from the more representative sampling of the plume partially offset by the more efficient sample collection method. Repeatability between duplicate and triplicate samples is also good. In the past, order-of-magnitude repeatability was a difficult goal to achieve. For the MIS samples, agreement was generally in the $30 \%$ range.

\section{Large-increment samples}

Large-increment samples (LIS) comprise a large number of increments, generally 100, taken with a small sampling tool. For the tests, 100 increments from a $10-\mathrm{cm}$ hand scoop fit into the standard sample bag. In these tests, sampling included the crater area, thus fully characterizing the plume. Table D-3 contains the data for these tests. In general, the residues calculated for the plumes from the LIS data were approximately equal to (within 20\%) or lower than those for the DSMs (23 of 28 comparisons). For HMX, the LIS method resulted in lower estimates for five plumes and approximately equal estimates for six. For RDX, eight were lower and four approximately equal. Table 16 contains comparative data for the averaged LISs and the DSMs. These data indicate that the differences in the results of the two sampling protocols are not very significant, generally less than a factor of two. An order of magnitude difference was previously thought to be good repeatability for explosives residue sampling. 


\begin{tabular}{|c|c|c|c|c|c|c|c|}
\hline \multicolumn{8}{|c|}{ Table 15. Replicate comparisons for MIS samples. } \\
\hline \multirow[b]{2}{*}{ Plume } & \multirow[b]{2}{*}{ Replicate } & \multicolumn{2}{|c|}{ Total residues } & \multicolumn{2}{|c|}{ RSD* } & \multicolumn{2}{|c|}{$\begin{array}{l}\text { Maximum difference } \\
\text { from mean }\end{array}$} \\
\hline & & HMX (mg) & RDX (mg) & HMX & RDX & HMX & RDX \\
\hline \multirow{3}{*}{$81-2$} & 1 & 2.2 & 3.2 & & & & \\
\hline & 2 & 2.9 & 6.0 & & & & \\
\hline & Average & 2.5 & 4.6 & $20 \%$ & $43 \%$ & $13 \%$ & $30 \%$ \\
\hline \multirow{4}{*}{$81-6$} & 1 & 75 & 360 & & & & \\
\hline & 2 & 55 & 290 & & & & \\
\hline & 3 & 65 & 220 & & & & \\
\hline & Average & 65 & 280 & $15 \%$ & $25 \%$ & $15 \%$ & $29 \%$ \\
\hline \multicolumn{2}{|c|}{ 81-mm average } & & & & & $14 \%$ & $30 \%$ \\
\hline \multirow{4}{*}{$105-4$} & 1 & 5.1 & 10 & & & & \\
\hline & 2 & 8.9 & 23 & & & & \\
\hline & 3 & 4.9 & 11 & & & & \\
\hline & Average & 6.3 & 15 & $36 \%$ & $48 \%$ & $41 \%$ & $53 \%$ \\
\hline \multirow{3}{*}{$105-5$} & 1 & 9.9 & 100 & & & & \\
\hline & 2 & 9.2 & 74 & & & & \\
\hline & Average & 9.6 & 87 & $5 \%$ & $21 \%$ & $4 \%$ & $15 \%$ \\
\hline \multirow{4}{*}{$105-7$} & 1 & 7.7 & 14 & & & & \\
\hline & 2 & 7.6 & 19 & & & & \\
\hline & 3 & 5.1 & 12 & & & & \\
\hline & Average & 6.8 & 15 & $22 \%$ & $24 \%$ & $25 \%$ & $27 \%$ \\
\hline $\begin{array}{l}\text { 105-mm } \\
\text { average }\end{array}$ & 6.8 & 15 & & & & $23 \%$ & $32 \%$ \\
\hline $\begin{array}{l}\text { Overall } \\
\text { average }\end{array}$ & & & & & & $19 \%$ & $31 \%$ \\
\hline
\end{tabular}

Replicate sampling was conducted on six of the 14 plumes, concentric zone sampling on three, and gray-zone sampling on one (see Methods section of this report for test descriptions). The objectives of these tests were to examine the repeatability of the LIS method and determine whether the residue levels are influenced by distance from the plume or the soot density of the plume. The latter tests have a direct impact on the bias analysis of the DSM protocol.

Replicate sampling consisted of three duplicate samples and three triplicate samples. The range of values about the mean for each plume is more consistent and slightly lower overall than for the MIS samples, averaging around $30 \%$ for both residue constituents. Triplicate samples and plumes with higher residue 
levels tended to have smaller ranges ( $17 \%$ vs. $47 \%$ on average for HMX and $19 \%$ vs. $55 \%$ on average for RDX). This likely reflects the difficulty in measuring residues at concentrations that are at or below the detection limits. The average of the plume LISs was compared with the DSM results.

\begin{tabular}{|c|c|c|}
\hline \multirow[b]{2}{*}{ 81-mm } & \multicolumn{2}{|c|}{ Difference with DSM } \\
\hline & HMX & RDX \\
\hline 1 & $54 \%$ & $53 \%$ \\
\hline 2 & $65 \%$ & $71 \%$ \\
\hline $3^{*}$ & $22 \%$ & $75 \%$ \\
\hline 4 & $1 \%$ & $2 \%$ \\
\hline 5 & $77 \%$ & $32 \%$ \\
\hline 6 & $2 \%$ & $20 \%$ \\
\hline 7 & $70 \%$ & $80 \%$ \\
\hline Average $(n=7)$ & $42 \%$ & $48 \%$ \\
\hline 105-mm & HMX & RDX \\
\hline 1 & $44 \%$ & $38 \%$ \\
\hline 2 & $57 \%$ & $26 \%$ \\
\hline $3^{*}$ & $18 \%$ & $27 \%$ \\
\hline $4^{\dagger}$ & $80 \%$ & $65 \%$ \\
\hline 5 & $82 \%$ & $75 \%$ \\
\hline 6 & $14 \%$ & $4 \%$ \\
\hline $7^{*}$ & $21 \%$ & $12 \%$ \\
\hline Average $(n=7)$ & $45 \%$ & $35 \%$ \\
\hline Overall $(n=14)$ & $43 \%$ & $41 \%$ \\
\hline \multicolumn{3}{|c|}{ * Weighted average of 3-zone radial sampling } \\
\hline
\end{tabular}

The calculated residues totals for each zone in the concentric zone tests were added to obtain the total residues for each of the three plumes (Table 17). These totals were used for comparison purposes with the DSM results in Table 16 (see values for 81-3 and 105-3, and -7). The results of the concentric-zone tests are shown in Table 17. For all three plumes, the difference in residues between adjacent zones approaches an order of magnitude. This is not surprising if the assumption is that the residue concentration is highest near the detonation point and falls off non-linearly to the edge of the plume. These results indicate that by oversampling the plume near the detonation point, the results will be skewed 
toward higher levels of residues, all other factors being equal. Note that even in this test, there was a tendency to collect twice as many increments in the area closest to the detonation point as in the two areas farther out from the crater.

\begin{tabular}{|c|c|c|c|c|c|}
\hline Plume/zone & Increments & Zone area $\left(\mathrm{m}^{2}\right)$ & Increments $/ \mathrm{m}^{2}$ & HMX (mg) & RDX (mg) \\
\hline \multicolumn{6}{|l|}{ Plume 81-5 } \\
\hline$<10-m$ & 135 & 187 & 0.72 & 2.6 & 16 \\
\hline 10- to $20-\mathrm{m}$ & 70 & 226 & 0.31 & 0.7 & 5.4 \\
\hline$>20-m$ & 58 & 377 & 0.15 & 0.0 & 1.2 \\
\hline Total & 263 & 790 & 0.33 & 3.2 & 22 \\
\hline \multicolumn{6}{|l|}{ Plume 105-3 } \\
\hline$<10-m$ & 39 & 282 & 0.14 & 6.5 & 21 \\
\hline 10- to $20-\mathrm{m}$ & 59 & 393 & 0.15 & 1.2 & 3.4 \\
\hline$>20-m$ & 43 & 263 & 0.16 & 0.53 & 0.27 \\
\hline Total & 141 & 938 & 0.15 & 8.3 & 25 \\
\hline \multicolumn{6}{|l|}{ Plume 105-7 } \\
\hline$<10-\mathrm{m}$ & 129 & 232 & 0.56 & 5.3 & 14.3 \\
\hline 10- to $20-\mathrm{m}$ & 80 & 367 & 0.22 & 1.1 & 3.7 \\
\hline$>20-m$ & 100 & 347 & 0.29 & 0.12 & 1.1 \\
\hline Total & 309 & 946 & 0.33 & 6.5 & 19.1 \\
\hline \multicolumn{6}{|l|}{ Average $(n=3)$} \\
\hline$<10-\mathrm{m}$ & 100 & 230 & 0.44 & 4.8 & 17 \\
\hline 10- to $20-\mathrm{m}$ & 70 & 330 & 0.21 & 1.0 & 4.2 \\
\hline$>20-m$ & 70 & 320 & 0.22 & 0.22 & 0.86 \\
\hline Total & 240 & 980 & 0.24 & 6.0 & 22 \\
\hline
\end{tabular}

The final factor that will be examined is the effect of plume density or "grayness" on sampling. Only one plume was sampled by gray zones using the LIS method, Plume 105-4. The results are given in Table 18.

\begin{tabular}{|c|c|c|}
\hline \multicolumn{3}{|c|}{ Table 18. Comparison of gray-zone results, Plume 105-4. } \\
\hline Method & HMX (mg) & RDX (mg) \\
\hline 3-Zone LIS & 2.8 & 7.6 \\
\hline Weighted DSM & 4.5 & 10 \\
\hline Standard DSM & 6.6 & 15 \\
\hline
\end{tabular}


These data reinforce the conclusion reached in the discrete sampling method section that there is a tendency toward sampling where the plume is darkest, or "where the good stuff is." If we assume that the weighting of the DSM sampling is correct and increases the accuracy of the method, it follows that the LIS results, which sampled the three zones separately and combined them for an overall residues value, are even more accurate in that any bias is minimized by separating out the gray zones within the plume and then sampling those zones in a systematic random manner. There remains a possibility of some bias as the sampler still has some choice as to where the sample is to be collected when a collection point is reached, but the options are limited due to the pattern that must be walked to collect the requisite number of samples.

In summary, the use of multiple-increment sampling for characterizing the residues within a detonation plume appears to be a feasible alternative to the discrete sampling method. The two protocols tested, 40-increment MIS sampling and 100-increment LIS sampling, proved repeatable and comparable to both the DSM samples and each other. Both methods are quick, allow for replicate sampling, and result in fewer samples for analysis. By reducing sampling time, more field QA can be done as well. The MIS sampling protocol has the advantage in speed (fewer increments), whereas the LIS has the advantage in forcing the collector to sample in a broader, more complete fashion, thus lowering the ability to bias the sampling.

\section{Implementation Tests}

Before making multiple-increment sampling the method of choice for sampling explosives residues on snow, additional work needed to be conducted to ensure the proposed method is adequate and repeatable. The method chosen for testing was the large-increment sampling protocol. The planned detonation of 155-mm HE rounds scheduled for March 2004 was used to test the implementation of this method for residue characterization. Two sets of seven rounds each were detonated, each set on a different day, and the plumes sampled for analysis.

\section{5-mm Comp-B}

Samples were collected for the 155-mm Comp-B tests using both the LIS and MIS methods. Subsurface samples, crater samples, and samples outside the plume were collected for QA (Table B-3). Table E-1 in Appendix E contains the data for these tests. Table 19 presents the averages and ranges for the plume data. 


\begin{tabular}{|c|c|c|c|c|c|c|c|}
\hline \multirow[b]{2}{*}{ Sample group } & \multirow[b]{2}{*}{$n=$} & \multicolumn{2}{|c|}{ Mean (mg) } & \multicolumn{2}{|c|}{ Range (mg) } & \multicolumn{2}{|c|}{ Maximum difference } \\
\hline & & HMX & RDX & HMX & RDX & HMX & RDX \\
\hline \multicolumn{8}{|c|}{ LISs } \\
\hline Plume 1 & 2 & 2.5 & 15 & 1.5 & 11 & $29 \%$ & $72 \%$ \\
\hline Plume 2 & 3 & ND & 4.4 & - & 3.7 & - & $52 \%$ \\
\hline Plume 3 & 2 & 1.8 & 3.6 & - & 2.5 & - & $36 \%$ \\
\hline Plume 4 & 3 & 1.7 & 28 & - & 46 & - & $92 \%$ \\
\hline Plume 5 & 2 & 0.35 & 33 & - & 2.0 & - & $3 \%$ \\
\hline Plume 6 & 3 & ND & 1.9 & - & 4.0 & - & $87 \%$ \\
\hline Plume 7 & 3 & 0.60 & 24 & - & 32 & - & $76 \%$ \\
\hline Mean-LISs & 7 & 1.0 & 16 & - & 14 & - & $59 \%$ \\
\hline \multicolumn{8}{|c|}{ MISs } \\
\hline Plume 3 & 2 & ND & 8.0 & - & 1.5 & - & $9 \%$ \\
\hline Plume 5 & 2 & ND & 10 & - & 0.10 & - & $1 \%$ \\
\hline Mean-MISs & 2 & - & 9.0 & - & 0.80 & - & $5 \%$ \\
\hline \multicolumn{8}{|c|}{ All } \\
\hline Maximum & 9 & 2.5 & 33 & 1.5 & 46 & $29 \%$ & $92 \%$ \\
\hline Minimum & 9 & ND & 1.9 & - & 0.10 & - & $1 \%$ \\
\hline Mean & 9 & - & 14 & - & 11 & - & $47 \%$ \\
\hline Median & 9 & 0.35 & 10 & - & 3.7 & - & $52 \%$ \\
\hline $\begin{array}{l}\text { Note: Values in ita } \\
\text { method. No TNT } \\
\text { detection limits, an }\end{array}$ & $\operatorname{ain}$ & $r$ mor & $\begin{array}{l}\text { poil } \\
\text { amp } \\
\text { to }\end{array}$ & $\begin{array}{l}\text { or } b \\
\text { ere }\end{array}$ & $\begin{array}{l}\text { etecti } \\
\text { ot an }\end{array}$ & $\begin{array}{l}\text { nits foc } \\
\text { ate va }\end{array}$ & $\begin{array}{l}\text { nalytical } \\
\text { e below }\end{array}$ \\
\hline
\end{tabular}

The two MIS duplicate samples agree very closely $(< \pm 8 \%)$. This is to be expected as they were taken as adjacent pairs. The LISs are not nearly as close. Samples were taken independently, sometimes by different personnel within the same plume. Two RDX values, one each in Plume 4 and Plume 7, account for the majority of the disparity in ranges. The replicates are all within an order of magnitude where explosives were detected. This is good repeatability for residues recovery, given the number of results at or below detection limits (12) and within $50 \%$ of the analytical detection limits (10), which makes comparative analyses difficult.

The data for the crater samples demonstrate that their contribution is important but not critical (Table 20). For detonations with significant residues (Plumes 1, 4, and 7), the contribution of the crater is relatively small ( $<9 \%$ on average). When the detonation is higher order $(>99.99 \%$ of explosives load consumed), the crater can contribute significantly to the overall residues, up to $20 \%$. 
When the residues are higher and the data are more critical in terms of range sustainability, the importance of data from the crater decreases as it becomes a less significant contributor to the residue mass within the plume. As it is impossible to determine the efficiency of a detonation in the field, it is prudent to always include the detonation point in the sample. This was done throughout the tests with the LISs.

\begin{tabular}{|c|c|c|c|c|c|c|c|c|}
\hline \multicolumn{8}{|c|}{ Table 20. Data for crater samples-155-mm Comp-B rounds. } \\
\hline & Crater & \multicolumn{2}{c|}{ Crater masses (mg) } & \multicolumn{4}{c|}{$\%$ of plume values* } \\
\cline { 3 - 9 } & area (m $\left.{ }^{2}\right)$ & HMX & RDX & TNT & Area & HMX & RDX & TNT \\
\hline Plume 1 & 13.8 & 0.13 & 0.21 & - & $1.1 \%$ & $5.1 \%$ & $1.3 \%$ & - \\
\hline Plume 2 & 13.8 & 0.16 & 0.56 & - & $0.80 \%$ & - & $12 \%$ & - \\
\hline Plume 4 & 15.6 & 0.32 & 1.7 & 0.03 & $0.94 \%$ & $18 \%$ & $6.1 \%$ & - \\
\hline Plume 6 & 13.3 & 0.12 & 0.38 & - & $0.80 \%$ & - & $20 \%$ & - \\
\hline Plume 7 & 12.4 & 0.02 & 0.22 & - & $0.80 \%$ & $3.3 \%$ & $0.92 \%$ & - \\
\hline Average & 13.8 & 0.15 & 0.61 & 0.007 & $0.88 \%$ & $5.3 \%$ & $8.1 \%$ & - \\
\hline * Crater mass/plume mass & & & & & & \\
\hline
\end{tabular}

Data for six of the seven plumes indicate that no residues were detected within a distance of up to $6 \mathrm{~m}$ outside the plume. The one detonation with residues outside the plume, Plume 1, was the result of high foot traffic in a small area adjacent to the plume where sampling took place. It was difficult for the samplers to determine the outline of the plume in that area and the sampling was thus likely erroneous. Wind drift of some residues may also have contributed to the error. In the case of Plume 1, the estimate for HMX outside the plume is almost equal to that inside (90\%), and the RDX outside the plume is equal to about $13 \%$ of that found inside the plume. Recovered residues dropped by an order of magnitude between the 0- to 3-m and the 3- to 6-m ranges in this case, indicating that the plume demarcation may have originally been satisfactory.

Subsurface samples taken beneath the MIS increments (Fig. 6) were clean, indicating that all the residues were recovered during sampling. Although the sample size is small $(n=2)$, the results are indicative of the improvement to be gained from using the smaller sampling tool for the multiple-increment sampling protocol (see Table 6). 


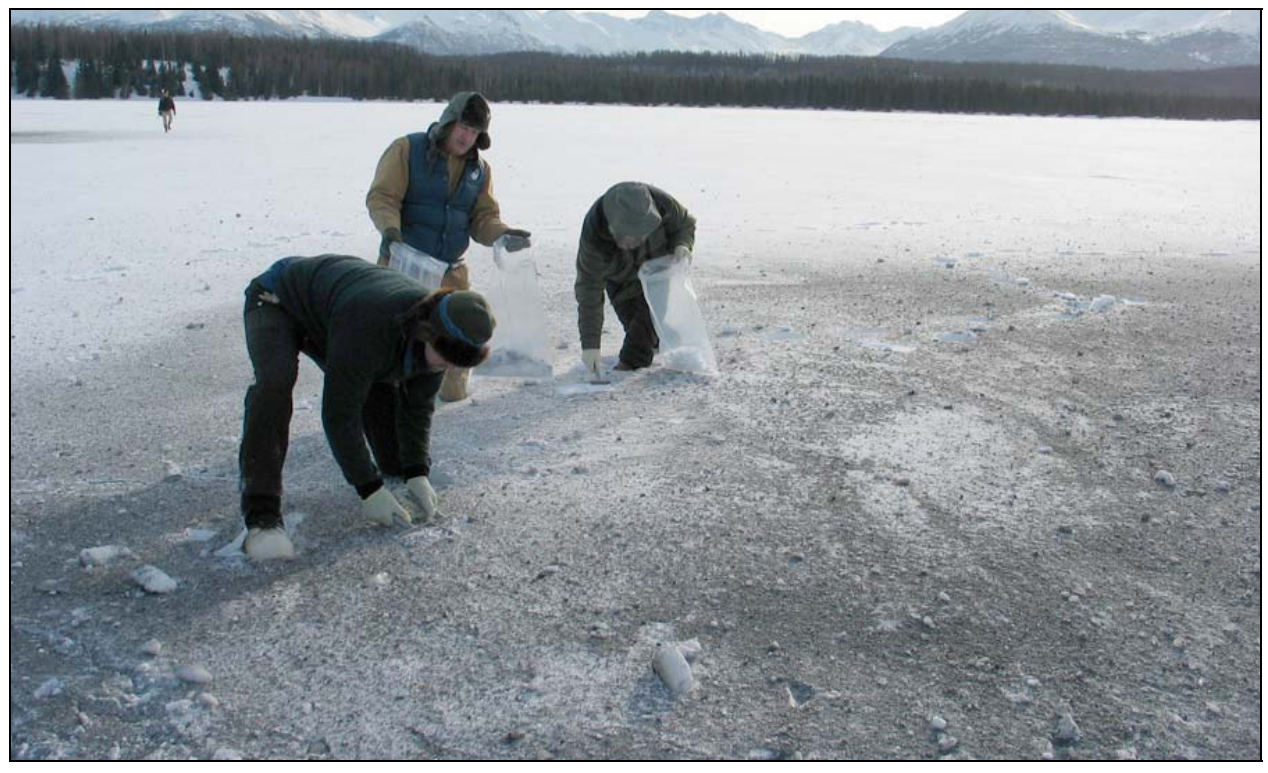

Figure 6. Collecting adjacent MIS samples and subsurface samples from 155-mm plume.

\section{5-mm TNT}

The sampling strategy for the TNT-filled rounds was the same as for the Comp-B filled rounds. Wind conditions were near ideal, with speeds below 1 $\mathrm{m} / \mathrm{s}$, and there was no drifting snow. All rounds were detonated within a threesecond window. Replicate MIS and LIS samples were used to characterize the plume. Table 21 contains the averages and ranges for the samples. The complete data set may be found in Table E-2.

Some differences between the averages and ranges of the Comp-B tests (Table 19) and the TNT tests are apparent. The range between the MIS samples for a given plume is somewhat greater for the TNT rounds, but the agreement between the MIS and LIS samples for Plumes 3 and 5 is good. Ranges for the LISs are consistent with the exception of two values out of the 21 (Plume 2 TNT and Plume 7 RDX). Some of the variability with the averages and ranges is due to the detection limits of the analysis equipment, which cuts off the lower values of the residues, thus skewing the averages lower and the ranges higher. This was also seen with the Comp-B tests and is a factor that will have to be taken into consideration when detonations are high- or near-high-order. In all, the sampling method looks consistent and repeatable for the TNT rounds. 


\begin{tabular}{|c|c|c|c|c|c|c|c|}
\hline \multirow[b]{2}{*}{ Sample group } & \multirow[b]{2}{*}{$n=$} & \multicolumn{2}{|c|}{ Mean (mg) } & \multicolumn{2}{|c|}{ Range (mg) } & \multicolumn{2}{|c|}{ Maximum difference } \\
\hline & & RDX & TNT & RDX & TNT & RDX & TNT \\
\hline \multicolumn{8}{|c|}{ LIS } \\
\hline Plume 1 & 3 & 6.0 & 8.8 & 7.6 & 15 & $126 \%$ & $104 \%$ \\
\hline Plume 2 & 3 & 6.9 & 11 & 1.8 & 14 & $9 \%$ & $69 \%$ \\
\hline Plume 3 & 2 & 5.9 & 4.5 & 2.1 & 0.6 & $13 \%$ & $7 \%$ \\
\hline Plume 4 & 3 & ND & 4.4 & - & 5.0 & - & $70 \%$ \\
\hline Plume 5 & 2 & ND & 6.4 & - & 3.3 & - & $26 \%$ \\
\hline Plume 6 & 3 & 4.3 & 2.3 & 4.1 & 1.7 & $53 \%$ & $39 \%$ \\
\hline Plume 7 & 2 & 12 & 4.4 & 19 & 1.2 & $59 \%$ & $14 \%$ \\
\hline Mean-LIS & 7 & $6.6^{\star}$ & 6.1 & 6.9 & 5.8 & $52 \%$ & $47 \%$ \\
\hline \multicolumn{8}{|c|}{ MIS } \\
\hline Plume 3 & 2 & 5.9 & 13 & 5 & 8.0 & $42 \%$ & $33 \%$ \\
\hline Plume 5 & 2 & ND & 5.9 & - & 0.50 & - & $4 \%$ \\
\hline Mean-MIS & 2 & - & 9.5 & - & 4.3 & - & $19 \%$ \\
\hline \multicolumn{8}{|c|}{ All } \\
\hline Maximum & 9 & 12 & 13 & 19 & 15 & $126 \%$ & $104 \%$ \\
\hline Minimum & 9 & ND & 2.3 & - & 0.50 & - & $4 \%$ \\
\hline Mean & 9 & $6.5^{\star}$ & 6.7 & $6.6^{*}$ & 5.5 & $50 \%$ & $41 \%$ \\
\hline Median & 9 & 5.9 & 5.9 & 4.5 & 3.3 & $47 \%$ & $39 \%$ \\
\hline \multicolumn{8}{|c|}{$\begin{array}{l}\text { Note: Values in italics contain one or more data point(s) at or below detection limits for the instrumenta- } \\
\text { tion. Where both soot and filtrate values are below detection limits, an ND is entered. All HMX values } \\
\text { were at or below detection limits. } \\
\text { * Means of the values above detection limits. }\end{array}$} \\
\hline
\end{tabular}

Analysis of the OTP and subsurface data are not as consistent. The data (Table 22) indicate that TNT detonation kinetics may differ significantly from Comp-B detonation kinetics (Taylor et al. 2004). Normally, TNT is not found in the soot fraction of the residues. In these tests, TNT was detected in every test in significant quantities compared to the plume surface samples. The indication is that during detonation, particles of unexploded TNT are distributed by the explosion. These particles are pale and would be difficult to see on the surface of the snow, making plume delineation problematic. These particles may also penetrate deeper into the snow than the soot. Only one OTP had any residue other than TNT in it, and neither subsurface sample had anything other than TNT in it. This indicates that the $\mathrm{C} 4$ donor charge fully detonated with little unreacted explosives remaining, and that the residues recovered are primarily from the projectile filler. 
Table 22. Sampling QA non-plume analysis for TNT-filled 155-mm implementation tests.

\begin{tabular}{|c|c|c|c|c|c|c|}
\hline \multirow[b]{2}{*}{ Sample group } & \multicolumn{3}{|c|}{ Estimated residues } & \multicolumn{3}{|c|}{ Percent of demarcated plume } \\
\hline & HMX (mg) & RDX (mg) & TNT (mg) & HMX & RDX & TNT \\
\hline \multicolumn{7}{|c|}{ Subsurface samples } \\
\hline Plume 3 & ND & ND & 210 & $0 \%$ & $0 \%$ & $4700 \%$ \\
\hline Plume 5 & ND & ND & 5.4 & $0 \%$ & $0 \%$ & $70 \%$ \\
\hline \multicolumn{7}{|c|}{ OTP samples } \\
\hline Plume 1 (10-20 m R) & ND & ND & 1.1 & $0 \%$ & $0 \%$ & $12 \%$ \\
\hline Plume 2 (0-3 m A) & 1.5 & ND & 7.3 & —* & $0 \%$ & $66 \%$ \\
\hline Plume $3(0-3 \mathrm{~m} \mathrm{~A})$ & ND & ND & 4.5 & $0 \%$ & $0 \%$ & $100 \%$ \\
\hline Plume 3 (3-6 m A) & ND & ND & 3.0 & $0 \%$ & $0 \%$ & $66 \%$ \\
\hline Plume $4(0-3 \mathrm{~m} \mathrm{~A})$ & ND & ND & 11 & $0 \%$ & $0 \%$ & $250 \%$ \\
\hline Plume 5 (0-3 m A) & ND & ND & 0.82 & $0 \%$ & $0 \%$ & $13 \%$ \\
\hline Plume 5 (3-6 m A) & ND & ND & 0.52 & $0 \%$ & $0 \%$ & $8.1 \%$ \\
\hline Plume $6(0-3 \mathrm{~m} \mathrm{~A})$ & ND & ND & 1.2 & $0 \%$ & $0 \%$ & $52 \%$ \\
\hline Plume 7 (10-20 m R) & ND & ND & 1.9 & $0 \%$ & $0 \%$ & $43 \%$ \\
\hline Average OTP & 0.21 & 0.0 & 4.5 & $0 \%$ & $0 \%$ & $87 \%$ \\
\hline
\end{tabular}

In summary, the multi-increment sampling technique proved very successful in representing the detonation plumes for 155-mm Comp-B-filled fuzed artillery projectiles. Problems were encountered with plume delineation and sampling depth for the 155-mm TNT-filled fuzed projectiles. These problems would also have been encountered with the DSM protocol and point to the need for modifying the sampling protocol to take the kinetics of the TNT projectile into account. More work needs to be done to refine the protocol for TNT-filled projectiles. 


\section{CONCLUSIONS}

Sampling residues on snow is a simple and effective method for characterizing detonation residues. Plumes can be demarcated visually with detonations involving Comp-B filler, although more care is necessary with TNT-filled rounds. The standard protocol for sampling, the discrete sampling method, is prone to bias but compares well with several other sampling protocols tested. Several multiple-increment sampling protocols were designed and tested, and all were demonstrated to be comparable and repeatable within less than an order of magnitude. Either the medium-increment or the large-increment sampling protocol will work effectively in place of the DSM protocol. The large-increment sampling protocol was tested on 155-mm high-explosive projectiles with very good results. The seven tests involving Comp-B-filled rounds were better at capturing residues than those involving the seven TNT-filled rounds, pointing to the need to modify the sampling protocol for those types of rounds. Repeatability of samples within a plume was also good, subject to influence by the detection limits of the analysis equipment. Several quality assurance tests were designed and applied to check the various sampling procedures throughout these tests and should be applied in the future to sampling of all detonation plumes. 


\section{REFERENCES}

Collins, C.M., and D.J. Calkins (1995) Winter tests of artillery firing into Eagle River Flats, Fort Richardson, Alaska. U.S. Army Cold Regions Research and Engineering Laboratory, Hanover, New Hampshire, Special Report 95-2.

Hewitt, A.D., T.F. Jenkins, T.A. Ranney, J.A. Stark, M.E. Walsh, S. Taylor, M.R. Walsh, D.J. Lambert, N.M. Perron, N.H. Collins, and R. Kern (2003) Estimates for explosives residues from the detonation of army munitions. U.S. Army Engineer Research and Development Center, Cold Regions Research and Engineering Laboratory, Hanover, New Hampshire, ERDC/CRREL Technical Report TR-03-16.

Jenkins, T.F., T.A. Ranney, M.E. Walsh, P.H. Miyares, A.D. Hewitt, and N.H. Collins (2000) Evaluating the use of snow-covered ranges to estimate the explosives residues that result from detonation of army munitions. U.S. Army Engineer Research and Development Center, Cold Regions Research and Engineering Laboratory, Hanover, New Hampshire, ERDC/CRREL Technical Report TR-00-15.

Jenkins, T.F., M.E. Walsh, P.H. Miyares, A.D. Hewitt, N.H. Collins, and T.A. Ranney (2002) Use of snow-covered ranges to estimate explosives residues from high-order detonations of army munitions. Thermochimica Acta, 384: 173185.

Natrella, M.G. (1963) Experimental statistics. U.S. Department of Commerce, Washington, D.C. National Bureau of Standards Handbook 91.

Taylor, S., A. Hewitt, J. Lever, C. Hayes, L. Perovich, P. Thorne, and C. Daghlian (2004) TNT particle size distributions from detonated 155-mm howitzer rounds. Chemosphere, 55: 357-367.

Walsh, M.E., and T.A. Ranney (1998) Determination of nitroaromatic, nitramine, and nitrate ester explosives in water using solid-phase extraction and GCECD. U.S. Army Cold Regions Research and Engineering Laboratory, Hanover, New Hampshire, Special Report 98-2.

Walsh, M.E., C.A. Ramsey, C.M. Collins, A.D. Hewitt, M.R. Walsh, K. Bjella, D.J. Lambert, and N.M. Perron (2005) Collection methods and laboratory processing of samples from Donnelly Training Area firing points: Alaska, 2003. U.S. Army Engineer Research and Development Center, Cold Regions Research and Engineering Laboratory, Hanover, New Hampshire, ERDC/CRREL Technical Report TR-05-6. 


\section{APPENDIX A. MUNITIONS DATA}

Tables A-1 and A-2 contain munitions data for all the tests conducted for this report. Table A-3 lists munitions explosives constituents and loading for these munitions. Only constituents with significant quantities $(>1 \mathrm{~g})$ are listed except for HMX. Note that HMX is an unmeasured constituent of RDX, the result of the manufacturing process, and may constitute up to $9 \%$ of the total RDX load. The number of blasting caps and amount of detonation cord used in each test varied according to the training needs of the troops and the discretion of the UXO technicians assisting with the operation. The majority of the explosives, however, were contributed by the test projectiles or rounds and the donor charge.

\begin{tabular}{|c|c|c|c|c|}
\hline NSN & DODIC & Nomenclature & Lot number & $\begin{array}{c}\text { Quantity } \\
\text { drawn }\end{array}$ \\
\hline 1315005637067 & $\mathrm{C} 256$ & Cartridge, 81 mm: HE M374 w/PD fuze & MA-84B153-025 & 7 \\
\hline 1315000284857 & C445 & Cartridge, 105 mm: M1 HE w/o fuze & LS-86D125-007 & 7 \\
\hline 1375014151232 & ML47 & $\begin{array}{l}\text { Cap, blasting, nonelectric, } 30-\mathrm{ft} \text { shock } \\
\text { tube }\end{array}$ & EBW97K060-008 & 8 \\
\hline 1375014151231 & MN03 & Cap, blasting, M13 & ENB00M002-007 & 8 \\
\hline 1375014151233 & MN06 & Cap, blasting, Non-electric, M13 & SHK98D001-001 & 15 \\
\hline 1375001809356 & M456 & $\begin{array}{l}\text { Cord, detonating, pentaerthyrie } \\
\text { tetranitrate }\end{array}$ & EBG03A002-015 & $610 \mathrm{~m}$ \\
\hline 1375014151235 & MN08 & $\begin{array}{l}\text { Igniter, time blasting fuse with shock, } \\
\text { M81 }\end{array}$ & LNO98E001-003 & 15 \\
\hline 1375007247040 & M023 & $\begin{array}{l}\text { Charge, demolition block, Comp C4, } \\
\text { M112 }\end{array}$ & MA-97A003-007A & 16 \\
\hline 1390010809447 & N340 & Fuze, point detonating, M739 & MA-84B007-013 & 7 \\
\hline $\begin{array}{r}\text { Notes: } \\
\text { Drawn frc } \\
\text { Supplem } \\
\text { Some mu }\end{array}$ & $\begin{array}{l}\text { Fort Rich } \\
\text { A Form } 5 \\
\text { al charge } \\
\text { ons quan }\end{array}$ & $\begin{array}{l}\text { rdson Ammo Supply Point. } \\
1 \text {-Request for Issue and Turn-in of Amn } \\
\text { used in all } 105-\mathrm{mm} \text { rounds. } \\
\text { ities used in subsequent tests not covere }\end{array}$ & $\begin{array}{l}\text { ition. } \\
\text { this report. }\end{array}$ & \\
\hline
\end{tabular}




\begin{tabular}{|c|c|c|c|c|}
\hline \multicolumn{5}{|c|}{ Table A-2. Munitions and explosives data-March tests. } \\
\hline NSN & DODIC & Nomenclature & Lot number & $\begin{array}{l}\text { Quantity } \\
\text { drawn }\end{array}$ \\
\hline 1320012574222 & D544 & $\begin{array}{l}\text { Projectile, } 155 \text { mm, M107, HE, w/o } \\
\text { fuze }\end{array}$ & IOP03E100-011 & 14 \\
\hline 1320014605087 & D544 & $\begin{array}{l}\text { Projectile, } 155 \mathrm{~mm}, \mathrm{M} 107, \mathrm{HE}, \text { w/o } \\
\text { fuze }\end{array}$ & IOP02K025-005 & 7 \\
\hline 1390010809447 & N340 & Fuze, point detonating, M739 & MA-84B007-013 & 21 \\
\hline 1375014151232 & ML47 & $\begin{array}{l}\text { Cap, blasting non-electric, } 30 \text { Foot, } \\
\text { M11 }\end{array}$ & EBW97K060-008 & 24 \\
\hline 1375014151231 & MN03 & Cap, blasting, non-electric, M13 & ENB00M002-007 & 36 \\
\hline 1375014151233 & MN06 & Cap, blasting, non-electric delay, M14 & SHK98D001-001 & 24 \\
\hline \multirow[t]{2}{*}{1375001809356} & M456 & $\begin{array}{l}\text { Cord, detonating, pentaerthyrie } \\
\text { tetranitrate }\end{array}$ & EBG03A002-015 & $305 \mathrm{~m}$ \\
\hline & & & ENB83H001-027 & $1830 \mathrm{~m}$ \\
\hline 1375014151235 & MN08 & $\begin{array}{l}\text { Igniter, time blasting fuse with shock, } \\
\text { M81 }\end{array}$ & LN098E001-003 & 25 \\
\hline 1375007247040 & M023 & $\begin{array}{l}\text { Charge, demolition block, Comp C4, } \\
\text { M112 }\end{array}$ & MA-97A003-007A & 30 \\
\hline $\begin{array}{l}\text { Notes: Drawn frc } \\
\text { Data from DA Fol } \\
\text { Supplemental ch } \\
\text { Some munitions }\end{array}$ & $\begin{array}{l}\text { Fort Ricl } \\
581-R e \\
\text { e used in } \\
\text { intities us }\end{array}$ & $\begin{array}{l}\text { rdson Ammo Supply Point. } \\
\text { uest for Issue and Turn-in of Ammunitio } \\
\text { all rounds. } \\
\text { d in subsequent tests not covered in thi }\end{array}$ & port. & \\
\hline
\end{tabular}


Table A-3 Explosives loading for munitions used in protocol tests.

\begin{tabular}{|c|c|c|c|c|c|c|}
\hline \multirow[b]{2}{*}{ DODIC } & \multirow[b]{2}{*}{ Nomenclature } & \multirow[b]{2}{*}{ Load (g) } & \multicolumn{4}{|c|}{ Consituent loads (g) } \\
\hline & & & TNT & RDX & HMX & NG* \\
\hline $\mathrm{C} 256$ & Cartridge, 81 mm, HE, M374, w/fuze PD F & 953 & 371 & 572 & & 46 \\
\hline \multirow[t]{2}{*}{ C445 } & Cartridge, 105 mm, M1, HE, w/o fuze & 2086 & 812 & 1253 & & \\
\hline & $\begin{array}{l}\text { Supplementary charge (for fuze well: Howitzer } \\
\text { rnds) }\end{array}$ & 136 & 136 & & & \\
\hline D544 & Projectile, 155 mm, M107, HE, w/o fuze & 6985 & 2724 & 4820 & & \\
\hline D544 & Projectile, 155 mm, M107, HE, w/o fuze & 6622 & 6622 & & & \\
\hline N340 & $\begin{array}{l}\text { Fuze, point detonating, M739 (used w/C445 \& } \\
\text { D544) }\end{array}$ & & & 21 & & \\
\hline N340 & Fuze, point detonating, M567 (supplied w/C256) & & $<1$ & 27 & & \\
\hline ML47 & $\begin{array}{l}\text { Cap, blasting, M11, non-electric, } 30-\mathrm{ft} \text {. shock } \\
\text { tube }\end{array}$ & 1.175 & & $<1$ & $<1$ & \\
\hline MN03 & Cap, blasting, M13 & 5.06 & & & & \\
\hline MN06 & Cap, blasting, non-electric delay, M14 & 11.73 & & & & \\
\hline M456 & $\begin{array}{l}\text { Cord, detonating, pentaerthyrie tetranitrate } \\
(1000 \mathrm{ft})\end{array}$ & 2900 & & & & \\
\hline MN08 & $\begin{array}{l}\text { Igniter, M81, time blasting fuse, shock tube } \\
\text { capable }\end{array}$ & 0.05 & & & & \\
\hline M023 & Charge, demolition, block, COMP C-4, 1.25 lb. & 570 & & 520 & & \\
\hline
\end{tabular}




\section{APPENDIX B. QUALITY ASSURANCE PROCEDURES FOR PROTOCOL TESTS}

The following tables contain a list of the QA procedures and their descriptions for each round or projectile detonated for the protocol and confirmation tests. The variability of the procedures for the tests reflects the development of the QA procedures during the course of the tests. In all, 139 QA tests consisting of over 9850 increments were performed on the 28 rounds used in these tests. A write-up of the recommended QA procedures for use with detonations on snow-covered ice will be presented in a future report.

\begin{tabular}{|c|c|c|}
\hline Detonation & Procedure & Description \\
\hline $81-1$ & $\begin{array}{l}\text { Subsurface sampling } \\
\text { Duplicate sampling } \\
\text { Annular OTP sampling }\end{array}$ & $\begin{array}{l}\text { One at each DSM surface sample } \\
\text { Adjacent samples } \\
\text { 0- to 3-m annulus }\end{array}$ \\
\hline $81-2$ & $\begin{array}{l}\text { Duplicate sampling } \\
\text { Annular OTP sampling }\end{array}$ & $\begin{array}{l}\text { MIS and LIS } \\
0 \text { - to 3-m annulus }\end{array}$ \\
\hline $81-3$ & $\begin{array}{l}\text { Duplicate sampling } \\
\text { Annular OTP sampling }\end{array}$ & $\begin{array}{l}\text { DSMs, adjacents, and LIS } \\
\text { 0- to 3-m annulus }\end{array}$ \\
\hline $81-4$ & $\begin{array}{l}\text { Duplicate sampling } \\
\text { Triplicate sampling }\end{array}$ & $\begin{array}{l}\text { Adjacents } \\
\text { LIS }\end{array}$ \\
\hline $81-5$ & $\begin{array}{l}\text { Subsurface sampling } \\
\text { Radial sampling } \\
\text { Annular OTP sampling } \\
\text { Radial OTP sampling }\end{array}$ & $\begin{array}{l}\text { One at each DSM surface sample } \\
\text { LIS (0- to } 10-/ 10-\text { to } 20-/>20-\mathrm{m} R \text { zones) } \\
0 \text { - to } 3 \text {-m annulus } \\
\text { 0- to } 10-\mathrm{m} \text { R OTP from detonation point }\end{array}$ \\
\hline $81-6$ & Triplicate sampling & MIS \\
\hline $81-7$ & Triplicate sampling & LIS \\
\hline
\end{tabular}




\begin{tabular}{|c|c|c|}
\hline Detonation & Procedure & Description \\
\hline $105-1$ & None & \\
\hline $105-2$ & None & \\
\hline $105-3$ & $\begin{array}{l}\text { Radial sampling } \\
\text { Annular OTP sampling }\end{array}$ & $\begin{array}{l}\text { LIS (0- to } 10-/ 10-\text { to } 20-/>20-m \text { R zones) } \\
\text { 0- to 3-m annulus }\end{array}$ \\
\hline $105-4$ & $\begin{array}{l}\text { Triplicate sampling } \\
\text { Gradient sampling }\end{array}$ & $\begin{array}{l}\text { Laps } \\
\text { LIS (gray-scale) }\end{array}$ \\
\hline $105-5$ & $\begin{array}{l}\text { Duplicate sampling } \\
\text { Triplicate sampling } \\
\text { Annular OTP sampling }\end{array}$ & $\begin{array}{c}\text { Adjacents } \\
\text { MIS and LIS } \\
\text { 0- to 3-m annulus }\end{array}$ \\
\hline $105-6$ & $\begin{array}{l}\text { Subsurface sampling } \\
\text { Duplicate sampling }\end{array}$ & $\begin{array}{l}\text { One at each DSM surface sample } \\
\text { LIS }\end{array}$ \\
\hline $105-7$ & $\begin{array}{l}\text { Duplicate sampling } \\
\text { Triplicate sampling } \\
\text { Radial sampling } \\
\text { Annular OTP sampling }\end{array}$ & $\begin{array}{c}\text { Adjacents } \\
\text { MIS } \\
\text { LIS (0- to } 10-/ 10 \text { - to } 20-/>20-m \text { R zones) } \\
\text { 0- to } 3-\text { m annulus }\end{array}$ \\
\hline
\end{tabular}




\begin{tabular}{|c|c|c|}
\hline Detonation & Procedure & Description \\
\hline $155-1 B$ & $\begin{array}{l}\text { Duplicate sampling } \\
\text { Radial OTP sampling }\end{array}$ & $\begin{array}{l}\text { LIS } \\
0 \text { - to } 10 \text { - and } 10-\text { to } 20-\mathrm{m} \text { radii from det point }\end{array}$ \\
\hline $155-2 B$ & $\begin{array}{l}\text { Triplicate sampling } \\
\text { Annular OTP sampling }\end{array}$ & $\begin{array}{l}\text { LIS } \\
\text { 0- to 3-m annulus }\end{array}$ \\
\hline $155-3 B$ & $\begin{array}{l}\text { Adjacent sampling } \\
\text { Subsurface sampling } \\
\text { Duplicate sampling } \\
\text { Annular OTP sampling }\end{array}$ & $\begin{array}{l}\text { MIS } \\
\text { Below each of one of the MIS samples } \\
\text { LIS } \\
\text { 0- to 3-m and 3- to 6-m annuli }\end{array}$ \\
\hline $155-4 B$ & $\begin{array}{l}\text { Triplicate sampling } \\
\text { Annular OTP sampling }\end{array}$ & $\begin{array}{l}\text { LIS } \\
0 \text { - to 3-m annulus }\end{array}$ \\
\hline $155-5 B$ & $\begin{array}{l}\text { Adjacent sampling } \\
\text { Subsurface sampling } \\
\text { Duplicate sampling } \\
\text { Annular OTP sampling }\end{array}$ & $\begin{array}{l}\text { MIS } \\
\text { Below each of one of the MIS samples } \\
\text { LIS } \\
\text { 0- to 3-m and 3- to 6-m annuli }\end{array}$ \\
\hline $155-6 B$ & $\begin{array}{l}\text { Triplicate sampling } \\
\text { Annular OTP sampling }\end{array}$ & $\begin{array}{l}\text { LIS } \\
0-\text { to 3-m annulus }\end{array}$ \\
\hline 155-7B & $\begin{array}{l}\text { Triplicate sampling } \\
\text { Radial OTP sampling }\end{array}$ & $\begin{array}{l}\text { LIS } \\
0 \text { - to } 10 \text { - and } 10-\text { to } 20-\mathrm{m} \text { radii from det point }\end{array}$ \\
\hline
\end{tabular}


Table B-4. QA Procedures conducted at each detonation-155-mm TNT tests.

\begin{tabular}{|c|c|c|}
\hline Detonation & Procedure & Description \\
\hline $155-1$ & $\begin{array}{l}\text { Triplicate sampling } \\
\text { Gradient sampling } \\
\text { Radial OTP sampling }\end{array}$ & $\begin{array}{l}\text { LIS } \\
\text { LIS } \\
\text { 10- to } 20-m \text { radius from detonation point }\end{array}$ \\
\hline $155-2$ & $\begin{array}{l}\text { Triplicate sampling } \\
\text { Annular OTP sampling }\end{array}$ & $\begin{array}{l}\text { LIS } \\
\text { 0- to 3-m annulus }\end{array}$ \\
\hline $155-3$ & $\begin{array}{l}\text { Adjacent sampling } \\
\text { Subsurface sampling } \\
\text { Duplicate sampling } \\
\text { Annular OTP sampling }\end{array}$ & $\begin{array}{l}\text { MIS } \\
\text { Below each of one of the MIS samples } \\
\text { LIS } \\
\text { 0- to 3-m and 3- to 6-m annuli }\end{array}$ \\
\hline $155-4$ & $\begin{array}{l}\text { Triplicate sampling } \\
\text { Annular OTP sampling }\end{array}$ & $\begin{array}{l}\text { LIS } \\
\text { 0- to 3-m annulus }\end{array}$ \\
\hline $155-5$ & $\begin{array}{l}\text { Adjacent sampling } \\
\text { Subsurface sampling } \\
\text { Duplicate sampling } \\
\text { Annular OTP sampling }\end{array}$ & $\begin{array}{l}\text { MIS } \\
\text { Below each of one of the MIS samples } \\
\text { LIS } \\
\text { 0- to 3-m and 3- to 6-m annuli }\end{array}$ \\
\hline $155-6$ & $\begin{array}{l}\text { Triplicate sampling } \\
\text { Annular OTP sampling }\end{array}$ & $\begin{array}{l}\text { LIS } \\
\text { 0- to 3-m annulus }\end{array}$ \\
\hline $155-7$ & $\begin{array}{l}\text { Triplicate sampling } \\
\text { Gradient sampling } \\
\text { Radial OTP sampling }\end{array}$ & $\begin{array}{l}\text { LIS } \\
\text { LIS } \\
\text { 10- to } 20 \text {-m radius from detonation point }\end{array}$ \\
\hline
\end{tabular}


Table B-5. List of all QA procedures conducted over the course of testing.

\begin{tabular}{|c|c|c|c|}
\hline Test type & Round tested & \# of reps. & Increments* \\
\hline Replicate DSMs & $81-3$ & 1 & $1 @ 17$ points \\
\hline \multirow{3}{*}{ Subsurface-DSMs } & $81-1$ & 1 & $1 @ 11$ points \\
\hline & $81-5$ & 1 & $1 @ 11$ points \\
\hline & $105-6$ & 1 & $1 @ 15$ points \\
\hline \multirow{14}{*}{ Adjacents-DSMs } & $81-1$ & 2 & 11 \\
\hline & $81-2$ & 1 & 12 \\
\hline & $81-3$ & 1 & 17 \\
\hline & $81-4$ & 2 & 11 \\
\hline & $81-5$ & 1 & 11 \\
\hline & $81-6$ & 1 & 11 \\
\hline & $81-7$ & 1 & 11 \\
\hline & $105-1$ & 1 & 15 \\
\hline & $105-2$ & 1 & 15 \\
\hline & $105-3$ & 1 & 17 \\
\hline & $105-4$ & 1 & 15 \\
\hline & $105-5$ & 2 & 18 \\
\hline & $105-6$ & 1 & 15 \\
\hline & $105-7$ & 1 & 18 \\
\hline \multirow{3}{*}{ Replicates_DSM adjacents } & $81-1$ & 1 & $1 @ 11$ points \\
\hline & $81-4$ & 1 & $1 @ 11$ points \\
\hline & $105-5$ & 1 & $1 @ 18$ points \\
\hline \multirow{15}{*}{ MIS } & $81-1$ & 1 & 38 \\
\hline & $81-2$ & 2 & 36 \\
\hline & $81-3$ & 1 & 40 \\
\hline & $81-4$ & 1 & 34 \\
\hline & $81-6$ & 3 & 40 \\
\hline & $81-7$ & 1 & 40 \\
\hline & $105-1$ & 11 & 40 \\
\hline & $105-2$ & 1 & 40 \\
\hline & $105-3$ & 1 & 40 \\
\hline & $105-4$ & 3 & 41 \\
\hline & $105-5$ & 3 & 41 \\
\hline & $105-6$ & 1 & 32 \\
\hline & $105-7$ & 3 & 35 \\
\hline & 155-3 Comp-B & 1 & 40 \\
\hline & 155-5 Comp-B & 1 & 40 \\
\hline
\end{tabular}


Table B-5 (cont'd). List of all QA procedures conducted over the course of testing.

\begin{tabular}{|c|c|c|c|}
\hline Test type & Round tested & \# of reps. & Increments* \\
\hline \multirow{2}{*}{ MIS } & 155-3 TNT & 1 & 40 \\
\hline & 155-5 TNT & 1 & 40 \\
\hline \multirow{4}{*}{ Adjacents-MIS } & 155-3 Comp-B & 1 & 40 \\
\hline & 155-5 Comp-B & 1 & 40 \\
\hline & 155-3 TNT & 1 & 40 \\
\hline & 155-5 TNT & 1 & 40 \\
\hline \multirow{24}{*}{ LIS } & $81-1$ & 1 & 109 \\
\hline & $81-2$ & 2 & 110 \\
\hline & $81-3$ & 2 & 103 \\
\hline & $81-4$ & 3 & 103 \\
\hline & $81-6$ & 1 & 73 \\
\hline & $81-7$ & 3 & 100 \\
\hline & $105-1$ & 1 & 100 \\
\hline & $105-2$ & 1 & 100 \\
\hline & $105-5$ & 3 & 120 \\
\hline & $105-6$ & 2 & 97 \\
\hline & 155-1 Comp-B & 1 & 100 \\
\hline & 155-2 Comp B & 2 & 100 \\
\hline & 155-3 Comp-B & 1 & 100 \\
\hline & 155-4 Comp-B & 2 & 105 \\
\hline & 155-5 Comp-B & 1 & 105 \\
\hline & 155-6 Comp-B & 2 & 111 \\
\hline & 155-7 Comp-B & 2 & 115 \\
\hline & 155-1 TNT & 2 & 105 \\
\hline & 155-2 TNT & 2 & 102 \\
\hline & 155-3 TNT & 1 & 100 \\
\hline & 155-4 TNT & 2 & 101 \\
\hline & 155-5 TNT & 1 & 100 \\
\hline & 155-6 TNT & 2 & 143 \\
\hline & 155-7 TNT & 1 & 96 \\
\hline \multirow{3}{*}{ LIS_Gray-scale zones } & $105-4$ & 1 & 137 \\
\hline & 155-1 TNT & 1 & 269 \\
\hline & 155-7 TNT & 1 & 180 \\
\hline \multirow{3}{*}{ LIS_Radial zones } & $81-5$ & 1 & 263 \\
\hline & $105-3$ & 1 & 141 \\
\hline & $105-7$ & 1 & 309 \\
\hline
\end{tabular}




\begin{tabular}{|c|c|c|c|}
\hline \multicolumn{4}{|c|}{ Table B-5 (cont'd). } \\
\hline Test type & Round tested & \# of reps. & Increments* \\
\hline \multirow{17}{*}{ OTP-0- to 3-m annulus } & $81-1$ & 1 & 40 \\
\hline & $81-2$ & 1 & 41 \\
\hline & $81-3$ & 1 & 80 \\
\hline & $81-5$ & 1 & 120 \\
\hline & $105-3$ & 1 & 66 \\
\hline & $105-5$ & 1 & 82 \\
\hline & $105-7$ & 1 & 66 \\
\hline & 155-2 Comp B & 1 & 100 \\
\hline & 155-3 Comp-B & 1 & 100 \\
\hline & 155-4 Comp-B & 1 & 100 \\
\hline & 155-5 Comp-B & 1 & 100 \\
\hline & 155-6 Comp-B & 1 & 73 \\
\hline & 155-2 TNT & 1 & 100 \\
\hline & 155-3 TNT & 1 & 100 \\
\hline & 155-4 TNT & 1 & 100 \\
\hline & 155-5 TNT & 1 & 100 \\
\hline & 155-6 TNT & 1 & 100 \\
\hline \multirow{4}{*}{ OTP-3- to 6-m annulus } & 155-1 Comp-B & 1 & 100 \\
\hline & 155-7 Comp-B & 1 & 100 \\
\hline & 155-1 TNT & 1 & 100 \\
\hline & 155-7 TNT & 1 & 100 \\
\hline \multirow{3}{*}{ OTP-0- to $10-\mathrm{m}$ radius } & $81-5$ & 1 & 35 \\
\hline & 155-1 Comp-B & 1 & 35 \\
\hline & 155-7 Comp-B & 1 & 50 \\
\hline \multirow{4}{*}{ OTP-10- to $20-\mathrm{m}$ radius } & 155-1 Comp-B & 1 & 73 \\
\hline & 155-7 Comp-B & 1 & 87 \\
\hline & 155-1 TNT & 1 & 98 \\
\hline & 155-7 TNT & 1 & 78 \\
\hline \multicolumn{4}{|c|}{$\begin{array}{l}\text { Notes: For } 81-\mathrm{mm} \text { and } 105-\mathrm{mm} \text { tests, the DSM protocol was the standard sampling protocol. For the } \\
\text { 155-mm tests, the LIS protocol was the standard protocol. QA was performed to verify these protocols. } \\
\text { * The number of increments is the average per rep. }\end{array}$} \\
\hline
\end{tabular}




\section{APPENDIX C. DATA FOR THE DISCRETE SAMPLING METHOD (DSM) TESTS}

The following tables contain data generated from residues sampling during the DSM baseline test phase of this project. Three tests were conducted concurrently with the DSM tests: discrete sampling, subsurface sampling beneath the discrete sampling area, and sampling outside the demarcated plume using a largeincrement composite sampling protocol. Each table is self-explanatory with the notes given at the bottom of the tables in the body of the report. Residue masses are given in milligrams.

\begin{tabular}{|c|c|c|c|c|c|c|}
\hline Plume \# & $\begin{array}{l}\text { Plume (OTP) } \\
\text { area }\left(\mathrm{m}^{2}\right)\end{array}$ & Sample type & \# Samples & Increments & $\begin{array}{l}\text { Sampled } \\
\text { area }\left(m^{2}\right)\end{array}$ & $\begin{array}{c}\% \text { of area } \\
\text { sampled }\end{array}$ \\
\hline \multirow{3}{*}{$81-1$} & 1506 & Discretes $\left(\mathrm{m}^{2}\right)$ & 11 & $1 \times 11$ & 11 & $0.73 \%$ \\
\hline & & Subsurface $\left(\mathrm{m}^{2}\right)$ & 11 & $1 \times 11$ & 11 & - \\
\hline & (489) & 0- to 3-m OTP & 1 & $40 \times 1$ & 1.6 & $0.33 \%$ \\
\hline \multirow{2}{*}{$81-2$} & 637 & Discretes $\left(m^{2}\right)$ & 12 & $1 \times 12$ & 12 & $1.9 \%$ \\
\hline & (354) & 0- to 3-m OTP & 1 & $41 \times 1$ & 1.6 & $0.46 \%$ \\
\hline \multirow{2}{*}{$81-3$} & 790 & Discretes $\left(\mathrm{m}^{2}\right)$ & $2 \times 17$ & $2 \times 17$ & 34 & $2.2 \%$ \\
\hline & (378) & 0- to 3-m OTP & 1 & 80 & 0.80 & $0.21 \%$ \\
\hline $81-4$ & 695 & Discretes $\left(\mathrm{m}^{2}\right)$ & 11 & $1 \times 11$ & 11 & $1.6 \%$ \\
\hline \multirow{4}{*}{$81-5$} & 693 & Discretes $\left(\mathrm{m}^{2}\right)$ & 11 & $1 \times 11$ & 11 & $1.6 \%$ \\
\hline & & Subsurface $\left(\mathrm{m}^{2}\right)$ & 11 & $1 \times 11$ & 11 & - \\
\hline & (312) & 0- to 3-m OTP & 1 & $120 \times 1$ & 1.2 & $0.38 \%$ \\
\hline & (129) & 0- to $10-\mathrm{m} \mathrm{R}$ OTP & 1 & $35 \times 1$ & 1.4 & $1.1 \%$ \\
\hline $81-6$ & 741 & Discretes $\left(\mathrm{m}^{2}\right)$ & 11 & $1 \times 11$ & 11 & $1.5 \%$ \\
\hline $81-7$ & 678 & Discretes $\left(\mathrm{m}^{2}\right)$ & 11 & $1 \times 11$ & 11 & $1.6 \%$ \\
\hline Total & & & 128 & 439 & & \\
\hline \multirow{3}{*}{ Average $^{\star}$} & 720 & Discretes $\left(\mathrm{m}^{2}\right)$ & 13 & 13 & 13 & $1.8 \%$ \\
\hline & & Subsurface $\left(\mathrm{m}^{2}\right)$ & 11 & 11 & 11 & $1.2 \%$ \\
\hline & (380) & 0 - to 3-m OTP & 1 & 79 & 1.6 & $0.42 \%$ \\
\hline $105-1$ & 731 & Discretes $\left(\mathrm{m}^{2}\right)$ & 15 & $1 \times 15$ & 15 & $2.1 \%$ \\
\hline $105-2$ & 443 & Discretes $\left(\mathrm{m}^{2}\right)$ & 15 & $1 \times 15$ & 15 & $3.4 \%$ \\
\hline \multirow{2}{*}{$105-3$} & 938 & Discretes $\left(\mathrm{m}^{2}\right)$ & 17 & $1 \times 15$ & 17 & $1.8 \%$ \\
\hline & (402) & 0- to 3-m OTP & 1 & $66 \times 1$ & 0.66 & $0.16 \%$ \\
\hline $105-4$ & 808 & Discretes $\left(\mathrm{m}^{2}\right)$ & 15 & $1 \times 15$ & 15 & $1.9 \%$ \\
\hline \multirow{2}{*}{$105-5$} & 872 & Discretes $\left(\mathrm{m}^{2}\right)$ & 18 & $1 \times 18$ & 18 & $2.1 \%$ \\
\hline & (457) & 0- to 3-m OTP & 1 & $82 \times 1$ & 0.82 & $0.18 \%$ \\
\hline
\end{tabular}




\begin{tabular}{|c|c|c|c|c|c|c|}
\hline \multicolumn{7}{|c|}{ Table C-1 (cont'd). } \\
\hline Plume \# & $\begin{array}{l}\text { Plume (OTP) } \\
\text { area }\left(\mathrm{m}^{2}\right)\end{array}$ & Sample type & \# Samples & Increments & $\begin{array}{l}\text { Sampled } \\
\text { area }\left(m^{2}\right)\end{array}$ & $\begin{array}{c}\% \text { of area } \\
\text { sampled }\end{array}$ \\
\hline \multirow{2}{*}{$105-6$} & \multirow{2}{*}{1310} & Discretes $\left(\mathrm{m}^{2}\right)$ & 15 & $1 \times 15$ & 15 & $1.2 \%$ \\
\hline & & Subsurface $\left(\mathrm{m}^{2}\right)$ & 15 & $1 \times 15$ & 15 & - \\
\hline \multirow{2}{*}{$105-7$} & 946 & Discretes $\left(\mathrm{m}^{2}\right)$ & 18 & $1 \times 18$ & 18 & $1.9 \%$ \\
\hline & (486) & 0- to 3-m OTP & 1 & $66 \times 1$ & 0.66 & $0.14 \%$ \\
\hline Total & & & 131 & 342 & & \\
\hline \multirow{3}{*}{ Average* } & 864 & Discretes $\left(\mathrm{m}^{2}\right)$ & 16 & 16 & 16 & $1.9 \%$ \\
\hline & & Subsurface $\left(\mathrm{m}^{2}\right)$ & 15 & 15 & 15 & $1.2 \%$ \\
\hline & $(450)$ & 0- to 3-m OTP & 1 & 71 & 0.71 & $0.16 \%$ \\
\hline
\end{tabular}


Table C-2. Estimated residues masses for DSM protocol tests.

\begin{tabular}{|c|c|c|c|}
\hline Plume \# & Sample type & HMX (mg) & RDX (mg) \\
\hline \multirow{3}{*}{$81-1$} & Discretes $\left(\mathrm{m}^{2}\right)$ & 11 & 20 \\
\hline & Subsurface $\left(\mathrm{m}^{2}\right)$ & 1.4 & 3.7 \\
\hline & OTP 0-3 m & 0.18 & - \\
\hline \multirow{2}{*}{$81-2$} & Discretes $\left(\mathrm{m}^{2}\right)$ & 5.6 & 7.2 \\
\hline & OTP 0-3 m & - & - \\
\hline \multirow{3}{*}{$81-3$} & Discretes $\left(m^{2}\right)-a$ & 1.1 & 8.1 \\
\hline & Discretes $\left(\mathrm{m}^{2}\right)-\mathrm{b}$ & 1.5 & 10 \\
\hline & OTP 0-3 m & - & - \\
\hline $81-4$ & Discretes $\left(\mathrm{m}^{2}\right)$ & 57 & 470 \\
\hline \multirow{4}{*}{$81-5$} & Discretes $\left(\mathrm{m}^{2}\right)$ & 7.3 & 31 \\
\hline & Subsurface $\left(\mathrm{m}^{2}\right)$ & 1.0 & 4.0 \\
\hline & OTP 0-3 m & - & 0.36 \\
\hline & OTP 0 - to $10-\mathrm{m}$ radius & - & - \\
\hline $81-6$ & Discretes $\left(\mathrm{m}^{2}\right)$ & 55 & 220 \\
\hline $81-7$ & Discretes $\left(\mathrm{m}^{2}\right)$ & 31 & 92 \\
\hline $105-1$ & Discretes $\left(\mathrm{m}^{2}\right)$ & 2.8 & 13 \\
\hline $105-2$ & Discretes $\left(\mathrm{m}^{2}\right)$ & 5.0 & 18 \\
\hline \multirow{2}{*}{$105-3$} & Discretes $\left(\mathrm{m}^{2}\right)$ & 6.9 & 33 \\
\hline & OTP 0-3 m & 0.15 & 2.2 \\
\hline $105-4$ & Discretes $\left(\mathrm{m}^{2}\right)$ & 6.6 & 15 \\
\hline \multirow{2}{*}{$105-5$} & Discretes $\left(\mathrm{m}^{2}\right)$ & 11 & 82 \\
\hline & OTP 0-3 m & 0.25 & 2.4 \\
\hline \multirow{2}{*}{$105-6$} & Discretes $\left(\mathrm{m}^{2}\right)$ & 11 & 25 \\
\hline & Subsurface $\left(\mathrm{m}^{2}\right)$ & 0.68 & 1.6 \\
\hline \multirow{2}{*}{$105-7$} & Discretes $\left(\mathrm{m}^{2}\right)$ & 5.3 & 17 \\
\hline & OTP 0-3 m & - & 0.43 \\
\hline
\end{tabular}




\begin{tabular}{|c|c|c|c|c|c|c|c|}
\hline Plume & Test & Zone & Area $\left(m^{2}\right)$ & $\begin{array}{c}\# \\
\text { Samples }\end{array}$ & $\begin{array}{c}\% \\
\text { Samples }\end{array}$ & $\%$ area & $\begin{array}{c}\text { Samplesl } \\
\text { area }^{\dagger}\end{array}$ \\
\hline \multirow{3}{*}{$81-1$} & \multirow{3}{*}{ Concentric } & 0 - to $10 \mathrm{~m}$ & 184 & 4 & $36 \%$ & $12 \%$ & 3.0 \\
\hline & & $10-$ to $20 \mathrm{~m}$ & 331 & 4 & $36 \%$ & $22 \%$ & 1.6 \\
\hline & & $>20 \mathrm{~m}$ & 991* & 3 & $27 \%$ & $66 \%$ & 0.41 \\
\hline \multirow{3}{*}{$81-2$} & \multirow{3}{*}{ Concentric } & 0 - to $10 \mathrm{~m}$ & 169 & 7 & $58 \%$ & $27 \%$ & 2.1 \\
\hline & & $10-$ to $20 \mathrm{~m}$ & 231 & 4 & $33 \%$ & $36 \%$ & 0.92 \\
\hline & & $>20 \mathrm{~m}$ & 237 & 1 & $8 \%$ & $37 \%$ & 0.22 \\
\hline \multirow{3}{*}{$81-3(a)$} & \multirow{3}{*}{ Concentric } & 0 - to $10 \mathrm{~m}$ & 187 & 6 & $35 \%$ & $24 \%$ & 1.5 \\
\hline & & 10- to $20 \mathrm{~m}$ & 226 & 5 & $30 \%$ & $29 \%$ & 1.0 \\
\hline & & $>20 \mathrm{~m}$ & 377 & 6 & $35 \%$ & $47 \%$ & 0.74 \\
\hline \multirow{3}{*}{$81-3(b)$} & \multirow{3}{*}{ Concentric } & 0 - to $10 \mathrm{~m}$ & 187 & 9 & $53 \%$ & $24 \%$ & 2.2 \\
\hline & & $10-$ to $20 \mathrm{~m}$ & 226 & 6 & $35 \%$ & $29 \%$ & 1.2 \\
\hline & & $>20 \mathrm{~m}$ & $377^{*}$ & 2 & $12 \%$ & $47 \%$ & 0.26 \\
\hline \multirow{3}{*}{$81-4$} & \multirow{3}{*}{ Concentric } & 0 - to $10 \mathrm{~m}$ & 144 & 4 & $36 \%$ & $21 \%$ & 1.7 \\
\hline & & $10-$ to $20 \mathrm{~m}$ & 194 & 5 & $45 \%$ & $28 \%$ & 1.6 \\
\hline & & $>20 \mathrm{~m}$ & $357^{*}$ & 2 & $18 \%$ & $51 \%$ & 0.35 \\
\hline \multirow{3}{*}{$81-5$} & \multirow{3}{*}{ Concentric } & 0 - to $10 \mathrm{~m}$ & 185 & 5 & $45 \%$ & $27 \%$ & 1.7 \\
\hline & & $10-$ to $20 \mathrm{~m}$ & 272 & 5 & $45 \%$ & $39 \%$ & 1.2 \\
\hline & & $>20 \mathrm{~m}$ & 235 & 1 & $9 \%$ & $34 \%$ & 0.26 \\
\hline \multirow{3}{*}{$81-6$} & \multirow{3}{*}{ Concentric } & 0 - to $10 \mathrm{~m}$ & 194 & 4 & $36 \%$ & $26 \%$ & 1.4 \\
\hline & & $10-$ to $20 \mathrm{~m}$ & 313 & 6 & $55 \%$ & $42 \%$ & 1.3 \\
\hline & & $>20 \mathrm{~m}$ & 234 & 1 & $9 \%$ & $32 \%$ & 0.28 \\
\hline \multirow{3}{*}{$81-7$} & \multirow{3}{*}{ Concentric } & 0 - to $10 \mathrm{~m}$ & 182 & 6 & $55 \%$ & $27 \%$ & 2.0 \\
\hline & & $10-$ to $20 \mathrm{~m}$ & 261 & 5 & $45 \%$ & $38 \%$ & 1.2 \\
\hline & & $>20 \mathrm{~m}$ & 236 & 0 & $0 \%$ & $35 \%$ & 0.00 \\
\hline \multirow{3}{*}{$105-3$} & \multirow{3}{*}{ Concentric } & 0 - to $10 \mathrm{~m}$ & 282 & 7 & $41 \%$ & $30 \%$ & 1.4 \\
\hline & & 10- to $20 \mathrm{~m}$ & 393 & 7 & $41 \%$ & $42 \%$ & 1.0 \\
\hline & & $>20 \mathrm{~m}$ & 263 & 3 & $18 \%$ & $28 \%$ & 0.64 \\
\hline \multirow{6}{*}{$105-4$} & \multirow{3}{*}{ Gray } & Dark & 97 & 4 & $27 \%$ & $12 \%$ & 2.2 \\
\hline & & Medium & 61 & 2 & $13 \%$ & $8 \%$ & 1.6 \\
\hline & & Light & 650 & 9 & $60 \%$ & $80 \%$ & 0.75 \\
\hline & \multirow{3}{*}{ Concentric } & 0 - to $10 \mathrm{~m}$ & 286 & 7 & $47 \%$ & $35 \%$ & 1.3 \\
\hline & & $10-$ to $20 \mathrm{~m}$ & 401 & 7 & $47 \%$ & $50 \%$ & 0.94 \\
\hline & & $>20 \mathrm{~m}$ & 121 & 1 & $6.7 \%$ & $15 \%$ & 0.45 \\
\hline \multirow{3}{*}{$105-7$} & \multirow{3}{*}{ Concentric } & 0 - to $10 \mathrm{~m}$ & 232 & 7 & $39 \%$ & $25 \%$ & 1.6 \\
\hline & & $10-$ to $20 \mathrm{~m}$ & 367 & 5 & $28 \%$ & $39 \%$ & 0.72 \\
\hline & & $>20 \mathrm{~m}$ & 347 & 6 & $33 \%$ & $36 \%$ & 0.92 \\
\hline \multicolumn{8}{|c|}{ * These plumes all extended beyond $30 \mathrm{~m}$. No samples were taken in that zone. } \\
\hline
\end{tabular}


Table C-4. Detonation proximity bias in DSM residues estimates.

\begin{tabular}{|c|c|c|c|c|}
\hline Plume & Test & Condition & HMX (mg) & RDX (mg) \\
\hline \multirow{3}{*}{$81-1$} & \multirow{3}{*}{ Concentric } & Weighted & 5.5 & 10 \\
\hline & & Standard DSM & 11 & 20 \\
\hline & & Difference & $100 \%$ & $100 \%$ \\
\hline \multirow{3}{*}{$81-2$} & \multirow{3}{*}{ Concentric } & Weighted & 4.1 & 7.1 \\
\hline & & Standard DSM & 5.6 & 7.2 \\
\hline & & Difference & $37 \%$ & $1.4 \%$ \\
\hline \multirow{3}{*}{$81-3 a$} & \multirow{3}{*}{ Concentric } & Weighted & 0.91 & 6.5 \\
\hline & & Standard DSM & 1.1 & 8.1 \\
\hline & & Difference & $21 \%$ & $25 \%$ \\
\hline \multirow{3}{*}{$81-3 b$} & \multirow{3}{*}{ Concentric } & Weighted & 1.1 & 17 \\
\hline & & Standard DSM & 1.5 & 10 \\
\hline & & Difference & $36 \%$ & $-42 \%$ \\
\hline \multirow{3}{*}{$81-4$} & \multirow{3}{*}{ Concentric } & Weighted & 46 & 446 \\
\hline & & Standard DSM & 57 & 473 \\
\hline & & Difference & $24 \%$ & $6.1 \%$ \\
\hline \multirow{3}{*}{$81-5$} & \multirow{3}{*}{ Concentric } & Weighted & 4.7 & 19 \\
\hline & & Standard DSM & 7.3 & 31 \\
\hline & & Difference & $55 \%$ & $63 \%$ \\
\hline \multirow{3}{*}{$81-6$} & \multirow{3}{*}{ Concentric } & Weighted & 43 & 170 \\
\hline & & Standard DSM & 55 & 220 \\
\hline & & Difference & $28 \%$ & $29 \%$ \\
\hline \multirow{3}{*}{$81-7$} & \multirow{3}{*}{ Concentric } & Weighted & 19 & 56 \\
\hline & & Standard DSM & 31 & 92 \\
\hline & & Difference & $63 \%$ & $64 \%$ \\
\hline \multicolumn{3}{|c|}{ Average difference: 81-mm } & $46 \%$ & $31 \%$ \\
\hline \multirow{3}{*}{$105-3$} & \multirow{3}{*}{ Concentric } & Weighted & 5.6 & 27 \\
\hline & & Standard DSM & 6.9 & 33 \\
\hline & & Difference & $23 \%$ & $22 \%$ \\
\hline \multirow{3}{*}{$105-4$} & \multirow{3}{*}{ Concentric } & Weighted & 5.1 & 11 \\
\hline & & Standard DSM & 6.6 & 15 \\
\hline & & Difference & $29 \%$ & $36 \%$ \\
\hline \multirow{3}{*}{$105-7$} & \multirow{3}{*}{ Concentric } & Weighted & 4.1 & 15 \\
\hline & & Standard DSM & 5.3 & 17 \\
\hline & & Difference & $29 \%$ & $13 \%$ \\
\hline \multicolumn{3}{|c|}{ Average difference: $105-\mathrm{mm}$} & $27 \%$ & $24 \%$ \\
\hline \multicolumn{3}{|c|}{ Average overall difference } & $38 \%$ & $28 \%$ \\
\hline
\end{tabular}




\section{APPENDIX D. DATA FOR PROTOCOL TESTS}

The following tables contain data generated from residues sampling during the protocol test phase of this project. Three tests were conducted concurrently with the DSM tests: Sampling adjacent to the DSM sample, plume characterization using a medium-increment composite sampling protocol, and plume characterization using a large-increment composite sampling protocol. Each table contains the number of samples taken, the increments per sample, the total area for each sample, and the percent of the demarcated plume sampled. Residues masses are given in milligrams.

\begin{tabular}{|c|c|c|c|c|c|c|}
\hline \multicolumn{7}{|c|}{ Table D-1. Data for adjacent samples. } \\
\hline Plume \# & \# Samples & Increments & $\begin{array}{c}\text { Sampled area } \\
\left(\mathrm{m}^{2}\right)\end{array}$ & $\begin{array}{l}\text { \% of plume } \\
\text { sampled }\end{array}$ & $\begin{array}{c}\text { HMX mass } \\
\text { (mg) }\end{array}$ & $\begin{array}{c}\text { RDX mass } \\
\text { (mg) }\end{array}$ \\
\hline \multirow{2}{*}{$81-1$} & \multirow{2}{*}{2} & \multirow{2}{*}{11 each } & \multirow{2}{*}{0.44 each } & \multirow{2}{*}{$0.03 \%$} & 15 & 23 \\
\hline & & & & & 6.8 & 14 \\
\hline $81-2$ & 1 & 12 & 0.48 & $0.08 \%$ & 9.4 & 4.9 \\
\hline \multirow{2}{*}{$81-3$} & \multirow{2}{*}{2} & \multirow{2}{*}{17 each } & \multirow{2}{*}{0.68} & \multirow{2}{*}{$0.09 \%$} & 1.8 & 7.6 \\
\hline & & & & & 2.2 & 16 \\
\hline \multirow{2}{*}{$81-4$} & \multirow{2}{*}{2} & \multirow{2}{*}{11 each } & \multirow{2}{*}{0.44 each } & \multirow{2}{*}{$0.06 \%$} & 20 & 640 \\
\hline & & & & & 97 & 720 \\
\hline $81-5$ & 1 & 11 & 0.44 & $0.06 \%$ & 10 & 45 \\
\hline $81-6$ & 1 & 11 & 0.44 & $0.06 \%$ & 67 & 280 \\
\hline $81-7$ & 1 & 11 & 0.44 & $0.06 \%$ & 45 & 130 \\
\hline $105-1$ & 1 & 15 & 0.60 & $0.08 \%$ & 6.1 & 11 \\
\hline $105-2$ & 1 & 15 & 0.60 & $0.14 \%$ & 6.6 & 14 \\
\hline $105-3$ & 1 & 17 & 0.68 & $0.07 \%$ & 9.6 & 17 \\
\hline $105-4$ & 1 & 15 & 0.60 & $0.07 \%$ & 8.4 & 18 \\
\hline \multirow{2}{*}{$105-5$} & \multirow{2}{*}{2} & \multirow{2}{*}{18} & \multirow{2}{*}{0.72 each } & \multirow{2}{*}{$0.08 \%$} & 29 & 180 \\
\hline & & & & & 24 & 54 \\
\hline $105-6$ & 1 & 15 & 0.60 & $0.05 \%$ & 17 & 32 \\
\hline \multirow{2}{*}{$105-7$} & \multirow{2}{*}{2} & \multirow{2}{*}{18} & \multirow{2}{*}{0.72 each } & \multirow{2}{*}{$0.08 \%$} & 10 & 23 \\
\hline & & & & & 8.5 & 12 \\
\hline
\end{tabular}




\begin{tabular}{|c|c|c|c|c|c|c|}
\hline \multicolumn{7}{|c|}{ Table D-2. Data for medium-increment (MIS) samples. } \\
\hline Plume \# & \# Samples & Increments & $\begin{array}{c}\text { Sampled area } \\
\left(\mathrm{m}^{2}\right)\end{array}$ & $\begin{array}{c}\% \text { of plume } \\
\text { sampled }\end{array}$ & $\begin{array}{c}\text { HMX mass } \\
\text { (mg) }\end{array}$ & $\begin{array}{c}\text { RDX mass } \\
\text { (mg) }\end{array}$ \\
\hline $81-1$ & 1 & 38 & 1.5 & $0.10 \%$ & 2.9 & 3.6 \\
\hline \multirow{2}{*}{$81-2$} & \multirow{2}{*}{2} & 35 & 1.4 & $0.22 \%$ & 2.2 & 3.2 \\
\hline & & 37 & 1.5 & $0.24 \%$ & 2.9 & 6.0 \\
\hline $81-3$ & 1 & 40 & 1.6 & $0.20 \%$ & 1.1 & 8.4 \\
\hline $81-4$ & 1 & 34 & 1.5 & $0.22 \%$ & 56 & 480 \\
\hline \multirow{3}{*}{$81-6$} & \multirow{3}{*}{3} & 40 & 1.6 & $0.22 \%$ & 75 & 335 \\
\hline & & 40 & 1.6 & $0.22 \%$ & 55 & 290 \\
\hline & & 40 & 1.6 & $0.22 \%$ & 65 & 220 \\
\hline $81-7$ & 1 & 40 & 1.6 & $0.24 \%$ & 16 & 43 \\
\hline $105-1$ & 1 & 40 & 1.6 & $0.22 \%$ & 2.3 & 11 \\
\hline $105-2$ & 1 & 40 & 1.6 & $0.36 \%$ & 4.6 & 16 \\
\hline $105-3$ & 1 & 40 & 1.6 & $0.17 \%$ & 6.3 & 20 \\
\hline \multirow{3}{*}{$105-4$} & \multirow{3}{*}{3} & 40 & 1.6 & $0.20 \%$ & 5.1 & 10 \\
\hline & & 40 & 1.6 & $0.20 \%$ & 8.9 & 23 \\
\hline & & 42 & 1.7 & $0.21 \%$ & 4.9 & 11 \\
\hline \multirow{3}{*}{$105-5$} & \multirow{3}{*}{3} & 42 & 1.7 & $0.19 \%$ & 9.9 & 104 \\
\hline & & 40 & 1.6 & $0.18 \%$ & 9.2 & 74 \\
\hline & & 40 & 1.6 & $0.18 \%$ & 9.6 & 540 \\
\hline $105-6$ & 1 & 32 & 1.3 & $0.10 \%$ & 8.6 & 17 \\
\hline \multirow{3}{*}{$105-7$} & \multirow{3}{*}{3} & 31 & 1.2 & $0.13 \%$ & 7.7 & 14 \\
\hline & & 36 & 1.4 & $0.15 \%$ & 7.6 & 19 \\
\hline & & 39 & 1.6 & $0.17 \%$ & 5.1 & 12 \\
\hline
\end{tabular}




\begin{tabular}{|c|c|c|c|c|c|c|}
\hline \multicolumn{7}{|c|}{ Table D-3. Data for large-increment (LIS) samples. } \\
\hline Plume \# & \# Samples & Increments & $\begin{array}{c}\text { Sampled area } \\
\left(\mathrm{m}^{2}\right)\end{array}$ & $\begin{array}{l}\% \text { of plume } \\
\text { sampled }\end{array}$ & $\begin{array}{c}\text { HMX mass } \\
\text { (mg) }\end{array}$ & $\begin{array}{l}\text { RDX mass } \\
\text { (mg) }\end{array}$ \\
\hline $81-1$ & 1 & 109 & 1.1 & $0.07 \%$ & 6.3 & 12 \\
\hline \multirow{2}{*}{$81-2$} & \multirow{2}{*}{2} & 106 & 1.1 & $0.17 \%$ & 2.7 & 2.9 \\
\hline & & 113 & 1.1 & $0.17 \%$ & 7.2 & 7.2 \\
\hline \multirow{2}{*}{$81-3$} & \multirow{2}{*}{2} & 104 & 1.0 & $0.13 \%$ & 0.92 & 11 \\
\hline & & 102 & 1.0 & $0.13 \%$ & 2.3 & 29 \\
\hline \multirow{3}{*}{$81-4$} & \multirow{3}{*}{3} & 100 & 1.0 & $0.14 \%$ & 66 & 520 \\
\hline & & 100 & 1.0 & $0.14 \%$ & 65 & 540 \\
\hline & & 110 & 1.1 & $0.16 \%$ & 40 & 370 \\
\hline $81-5$ & 1 & 263 & 2.6 & $0.38 \%$ & 3.2 & 22 \\
\hline $81-6$ & 1 & 73 & 0.73 & $0.10 \%$ & 56 & 270 \\
\hline \multirow{3}{*}{$81-7$} & \multirow{3}{*}{3} & 100 & 1.0 & $0.15 \%$ & 17 & 42 \\
\hline & & 100 & 1.0 & $0.15 \%$ & 15 & 44 \\
\hline & & 100 & 1.0 & $0.15 \%$ & 12 & 33 \\
\hline $105-1$ & 1 & 100 & 1.0 & $0.14 \%$ & 4.4 & 8.9 \\
\hline $105-2$ & 1 & 100 & 1.0 & $0.23 \%$ & 2.8 & 14 \\
\hline $105-3$ & 1 & 141 & 1.4 & $0.15 \%$ & 8.3 & 25 \\
\hline $105-4$ & 1 & 137 & 1.4 & $0.17 \%$ & 2.8 & 7.6 \\
\hline \multirow{3}{*}{$105-5$} & \multirow{3}{*}{3} & 105 & 1.1 & $0.13 \%$ & 22 & 150 \\
\hline & & 111 & 1.1 & $0.13 \%$ & 28 & 200 \\
\hline & & 144 & 1.4 & $0.17 \%$ & 28 & 190 \\
\hline \multirow{2}{*}{$105-6$} & \multirow{2}{*}{2} & 97 & 0.97 & $0.07 \%$ & 15 & 30 \\
\hline & & 97 & 0.97 & $0.07 \%$ & 10 & 18 \\
\hline $105-7$ & 1 & 309 & 3.1 & $0.33 \%$ & 6.5 & 19 \\
\hline
\end{tabular}




\section{APPENDIX E. DATA FOR IMPLEMENTATION TESTS}

The following two tables contain data derived from the implementation tests. In these tables, $M_{R}$ is the mass of the residues collected in the sample (both filtrate and soot fractions), $\mathrm{C}_{\mathrm{S}}$ is the surface concentration calculated for the area sampled, and $\mathrm{M}_{\mathrm{T}}$ is the total mass calculated for either the crater, the plume, or the area outside the plume sampled. Italics indicates extract concentrations of the analytes below or near $(+50 \%)$ the detection limit $(30 \mu \mathrm{g} / \mathrm{L})$ of the analytical method. Residues are given in micrograms.

\begin{tabular}{|c|c|c|c|c|c|c|c|c|c|c|}
\hline \multirow[b]{2}{*}{$\begin{array}{c}\text { Sample } \\
\text { type }\end{array}$} & \multirow{2}{*}{$\begin{array}{c}\begin{array}{c}\text { Areas } \\
\left(\mathrm{m}^{2}\right)\end{array} \\
\text { Plumel } \\
\text { sample }\end{array}$} & \multicolumn{3}{|c|}{ HMX } & \multicolumn{3}{|c|}{ RDX } & \multicolumn{3}{|c|}{ TNT } \\
\hline & & $\begin{array}{c}M_{R} \\
(\mu \mathrm{g})\end{array}$ & $\begin{array}{c}C_{S} \\
\left(\mu \mathrm{g} / \mathrm{m}^{2}\right)\end{array}$ & $\begin{array}{c}M_{\mathrm{T}} \\
(\mathrm{mg})\end{array}$ & $\begin{array}{c}M_{R} \\
(\mu \mathrm{g})\end{array}$ & $\begin{array}{c}C_{S} \\
\left(\mu \mathrm{g} / \mathrm{m}^{2}\right)\end{array}$ & $\begin{array}{c}M_{\mathrm{T}} \\
(\mathrm{mg})\end{array}$ & $\begin{array}{c}M_{R} \\
(\mu \mathrm{g})\end{array}$ & $\begin{array}{c}C_{S} \\
\left(\mu \mathrm{g} / \mathrm{m}^{2}\right)\end{array}$ & $\begin{array}{c}M_{\mathrm{T}} \\
(\mathrm{mg})\end{array}$ \\
\hline Plume 1 & 1275 & & & & & & & & & \\
\hline Crater & 0.90 & 8.4 & 9.4 & 0.13 & 13 & 15 & 0.21 & ND & - & - \\
\hline LIS & 0.94 & 1.3 & 1.4 & 1.8 & 7.3 & 7.7 & 9.8 & $N D$ & - & - \\
\hline LIS & 1.00 & 2.6 & 2.6 & 3.3 & 17 & 17 & 21 & ND & - & - \\
\hline OTP-10R & 0.35 & 0.67 & 1.9 & 2.4 & 23 & 66 & 3.7 & ND & - & - \\
\hline OTP-20R & 0.73 & ND & - & - & 0.71 & 0.97 & 0.37 & ND & - & - \\
\hline Plume 2 & 1731 & & & & & & & & & \\
\hline Crater & 0.30 & 3.6 & 12 & .16 & 12 & 41 & 0.56 & ND & - & - \\
\hline LIS & 1.00 & $\mathrm{ND}$ & - & - & 3.1 & 3.1 & 5.4 & ND & - & - \\
\hline LIS & 1.00 & ND & - & - & 1.2 & 1.2 & 2.1 & ND & - & - \\
\hline LIS & 1.00 & ND & - & - & 3.3 & 3.3 & 5.8 & ND & - & - \\
\hline OTP-3A & 2.25 & ND & - & - & ND & - & - & $N D$ & - & - \\
\hline Plume 3 & 1835 & & & & & & & & & \\
\hline MIS & 0.90 & ND & - & - & 1.9 & 4.8 & 8.8 & ND & - & - \\
\hline MIS & 0.90 & ND & - & - & 3.6 & 4.0 & 7.3 & ND & - & - \\
\hline $\begin{array}{c}\text { Sub- } \\
\text { surface }\end{array}$ & 0.40 & ND & - & - & ND & - & - & ND & - & - \\
\hline LIS & 1.00 & ND & - & - & 1.3 & 1.3 & 2.3 & ND & - & - \\
\hline LIS & 1.00 & 2.0 & 2.0 & 3.7 & 2.6 & 2.6 & 4.8 & ND & - & - \\
\hline OTP-3А & 1.00 & ND & - & - & ND & - & - & ND & - & - \\
\hline OTP-6A & 1.00 & ND & - & - & $N D$ & - & - & ND & - & - \\
\hline
\end{tabular}




\begin{tabular}{|c|c|c|c|c|c|c|c|c|c|c|}
\hline \multicolumn{11}{|c|}{ Table E-1 (cont'd). } \\
\hline \multirow[b]{2}{*}{$\begin{array}{c}\text { Sample } \\
\text { type }\end{array}$} & \multirow{2}{*}{$\begin{array}{c}\begin{array}{c}\text { Areas } \\
\left(\mathrm{m}^{2}\right)\end{array} \\
\text { Plumel } \\
\text { sample }\end{array}$} & \multicolumn{3}{|c|}{ HMX } & \multicolumn{3}{|c|}{ RDX } & \multicolumn{3}{|c|}{ TNT } \\
\hline & & $\begin{array}{c}M_{R} \\
(\mu g)\end{array}$ & $\underset{\left(\mu \mathrm{g} / \mathrm{m}^{2}\right)}{\mathrm{C}_{\mathrm{S}}}$ & $\begin{array}{l}M_{\mathrm{T}} \\
(\mathrm{mg})\end{array}$ & $\begin{array}{c}M_{R} \\
(\mu g)\end{array}$ & $\begin{array}{c}C_{S} \\
\left(\mu \mathrm{g} / \mathrm{m}^{2}\right)\end{array}$ & $\begin{array}{l}M_{\mathrm{T}} \\
(\mathrm{mg})\end{array}$ & $\begin{array}{c}M_{R} \\
(\mu g)\end{array}$ & $\underset{\left(\mu \mathrm{g} / \mathrm{m}^{2}\right)}{\mathrm{C}_{\mathrm{S}}}$ & $\begin{array}{c}M_{\mathrm{T}} \\
(\mathrm{mg})\end{array}$ \\
\hline Plume 4 & 1654 & & & & & & & & & \\
\hline Crater & 0.68 & 14 & 20 & 0.32 & 73 & 110 & 1.7 & 1.4 & 2.1 & 0.03 \\
\hline LIS & 1.04 & 3.3 & 3.1 & 5.2 & 33 & 32 & 53 & ND & - & - \\
\hline LIS & 1.06 & ND & - & - & 15 & 14 & 23 & ND & - & - \\
\hline LIS & 1.05 & ND & - & - & 4.3 & 4.1 & 6.7 & ND & - & - \\
\hline OTP-3A & 2.25 & ND & - & - & ND & - & - & ND & - & - \\
\hline Plume 5 & 1638 & & & & & & & & & \\
\hline MIS & 0.90 & ND & - & - & 5.4 & 6.0 & 9.9 & ND & - & - \\
\hline MIS & 0.90 & ND & - & - & 5.5 & 6.1 & 10 & ND & - & - \\
\hline $\begin{array}{l}\text { Sub- } \\
\text { surface }\end{array}$ & 0.40 & ND & - & - & ND & - & - & ND & - & - \\
\hline LIS & 1.00 & ND & - & - & 21 & 21 & 34 & ND & - & - \\
\hline LIS & 1.10 & 0.48 & 0.44 & 0.71 & 22 & 20 & 32 & ND & - & - \\
\hline OTP-3A & 1.00 & ND & - & - & ND & - & - & ND & - & - \\
\hline OTP-6A & 1.00 & ND & - & - & ND & - & - & ND & - & - \\
\hline Plume 6 & 1656 & & & & & & & & & \\
\hline Crater & 0.30 & 2.7 & 8.8 & 0.12 & 8.7 & 29 & 0.38 & ND & - & - \\
\hline LIS & 1.10 & ND & - & - & 0.39 & 0.35 & 0.59 & ND & - & - \\
\hline LIS & 1.05 & ND & - & - & 2.9 & 2.8 & 4.6 & ND & - & - \\
\hline LIS & 1.28 & ND & - & - & 0.44 & 0.34 & 0.57 & ND & - & - \\
\hline OTP-3A & 0.73 & ND & - & - & ND & - & - & ND & - & - \\
\hline Plume 7 & 1556 & & & & & & & & & \\
\hline Crater & 0.50 & 0.75 & 1.5 & 0.02 & 8.9 & 18 & 0.22 & ND & - & - \\
\hline LIS & 1.09 & ND & - & - & 3.5 & 3.2 & 5.0 & ND & - & - \\
\hline LIS & 1.30 & 1.5 & 1.2 & 1.8 & 31 & 24 & 37 & ND & - & - \\
\hline LIS & 1.00 & ND & - & - & 19 & 19 & 29 & ND & - & - \\
\hline OTP-10R & 0.87 & ND & - & - & $N D$ & - & - & ND & - & - \\
\hline OTP-20R & 0.50 & ND & - & - & ND & - & - & ND & - & - \\
\hline
\end{tabular}


Table E-2. Estimated total residues masses for detonation tests-155-mm TNT rounds.

\begin{tabular}{|c|c|c|c|c|c|c|c|c|c|c|}
\hline \multirow[b]{2}{*}{$\begin{array}{c}\text { Sample } \\
\text { type }\end{array}$} & \multirow{2}{*}{$\begin{array}{c}\begin{array}{c}\text { Areas } \\
\left(\mathrm{m}^{2}\right)\end{array} \\
\text { Plumel } \\
\text { sample }\end{array}$} & \multicolumn{3}{|c|}{ HMX } & \multicolumn{3}{|c|}{ RDX } & \multicolumn{3}{|c|}{ TNT } \\
\hline & & $\begin{array}{c}M_{R} \\
(\mu g)\end{array}$ & $\underset{\left(\mu \mathrm{g} / \mathrm{m}^{2}\right)}{\mathrm{C}_{\mathrm{S}}}$ & $\begin{array}{c}M_{\mathrm{T}} \\
(\mathrm{mg})\end{array}$ & $\begin{array}{c}M_{R} \\
(\mu g)\end{array}$ & $\underset{\left(\mu \mathrm{g} / \mathrm{m}^{2}\right)}{\mathrm{C}_{\mathrm{S}}}$ & $\begin{array}{c}M_{\mathrm{T}} \\
(\mathrm{mg})\end{array}$ & $\begin{array}{c}M_{R} \\
(\mu g)\end{array}$ & $\underset{\left(\mu \mathrm{g} / \mathrm{m}^{2}\right)}{\mathrm{C}_{\mathrm{S}}}$ & $\begin{array}{c}M_{\mathrm{T}} \\
(\mathrm{mg})\end{array}$ \\
\hline Plume 1 & 1234 & & & & & & & & & \\
\hline LIS-1 & 1.1 & 1.8 & 1.6 & 2.0 & 9.5 & 8.7 & 11 & 2.9 & 2.6 & 3.3 \\
\hline LIS-2 & 0.91 & ND & - & - & 2.8 & 2.8 & 3.4 & 4.2 & 4.2 & 5.2 \\
\hline LIS-3 & 0.52 & 2.4 & 2.4 & 2.9 & 3.0 & 3.0 & 3.7 & 15 & 15 & 18 \\
\hline LIS-Lt & 1.26 & ND & 0 & 0 & ND & - & - & 16.2 & 13 & 11 \\
\hline LIS-Med & 0.91 & 6.2 & 6.8 & 2.2 & 12 & 13 & 4.2 & 3.6 & 4.0 & 1.3 \\
\hline LIS-DK & 0.52 & ND & - & - & ND & - & - & 2.3 & 4.3 & 0.30 \\
\hline OTP-20R & 0.98 & ND & - & - & ND & - & - & 2.92 & 3.0 & 1.1 \\
\hline Plume 2 & 1600 & & & & & & & & & \\
\hline Crater & 0.20 & 1.4 & 7 & 1.5 & 4.5 & 22 & 0.27 & 6 & 30 & 0.36 \\
\hline LIS-1 & 1.0 & 1.8 & 1.8 & 2.9 & 4.7 & 4.7 & 7.5 & 6.5 & 6.5 & 10 \\
\hline LIS-2 & 1.0 & 1.5 & 1.4 & 2.3 & 3.7 & 3.6 & 5.7 & 3 & 3.0 & 4.7 \\
\hline LIS-3 & 1.0 & 2.1 & 2.1 & 3.3 & 4.7 & 4.7 & 7.5 & 12 & 12 & 19 \\
\hline OTP-3A & 1.0 & 2.0 & 2.0 & 1.5 & ND & - & - & 10 & 10 & 7.3 \\
\hline Plume 3 & 1311 & & & & & & & & & \\
\hline MIS & 0.90 & 1.7 & 1.9 & 2.5 & 5.8 & 6.4 & 8.4 & 5.8 & 6.5 & 8.5 \\
\hline MIS & 0.90 & ND & - & - & 2.4 & 2.6 & 3.4 & 12 & 13 & 17 \\
\hline $\begin{array}{c}\text { Sub- } \\
\text { surface }\end{array}$ & 0.40 & ND & - & - & ND & - & - & 63 & 160 & 210 \\
\hline LIS-1 & 1.0 & ND & - & - & 5.4 & 5.43 & 7.1 & 3.2 & 3.2 & 4.2 \\
\hline LIS-2 & 1.0 & 1.5 & 1.5 & 1.9 & 7.0 & 7.0 & 9.2 & 3.7 & 3.7 & 4.8 \\
\hline OTP-3A & 1.0 & ND & - & - & ND & - & - & 7.8 & 7.8 & 4.5 \\
\hline OTP-6A & 1.0 & ND & - & - & ND & - & - & 4.8 & 4.8 & 3.0 \\
\hline Plume 4 & 1201 & & & & & & & & & \\
\hline LIS-1 & 1.0 & ND & - & - & ND & - & - & 15 & 10 & 1.3 \\
\hline LIS-2 & 1.0 & ND & - & - & ND & - & - & 4.7 & 4.7 & 5.6 \\
\hline LIS-3 & 1.4 & ND & - & - & ND & - & - & 5.3 & 5.2 & 6.3 \\
\hline OTP-3A & 1.0 & ND & - & - & ND & - & - & 23 & 23 & 11 \\
\hline Plume 5 & 1108 & & & & & & & & & \\
\hline MIS & 0.9 & ND & - & - & ND & - & - & 5 & 5.5 & 6.1 \\
\hline MIS & 0.90 & ND & - & - & ND & - & - & 4.6 & 5.1 & 5.6 \\
\hline $\begin{array}{c}\text { Sub- } \\
\text { surface }\end{array}$ & 0.40 & ND & - & - & ND & - & - & 2 & 4.9 & 5.4 \\
\hline LIS-1 & 1.0 & ND & - & - & ND & - & - & 7.4 & 7.2 & 8.0 \\
\hline LIS-2 & 1.0 & ND & - & - & ND & - & - & 4.3 & 4.3 & 4.7 \\
\hline
\end{tabular}




\begin{tabular}{|c|c|c|c|c|c|c|c|c|c|c|}
\hline \multicolumn{11}{|c|}{ Table E-2 (cont'd). } \\
\hline \multirow[b]{2}{*}{$\begin{array}{c}\text { Sample } \\
\text { type }\end{array}$} & \multirow{2}{*}{$\begin{array}{c}\text { Areas } \\
\left(\mathbf{m}^{2}\right)\end{array}$} & \multicolumn{3}{|c|}{ HMX } & \multicolumn{3}{|c|}{ RDX } & \multicolumn{3}{|c|}{ TNT } \\
\hline & & $\begin{array}{c}M_{R} \\
(\mu g)\end{array}$ & $\begin{array}{c}\mathrm{C}_{\mathrm{S}} \\
\left(\mu \mathrm{g} / \mathrm{m}^{2}\right)\end{array}$ & $\begin{array}{c}M_{\mathrm{T}} \\
(\mathrm{mg})\end{array}$ & $\begin{array}{c}M_{R} \\
(\mu g)\end{array}$ & $\underset{\left(\mu \mathrm{g} / \mathrm{m}^{2}\right)}{\mathrm{C}_{\mathrm{S}}}$ & $\begin{array}{c}M_{\mathrm{T}} \\
(\mathrm{mg})\end{array}$ & $\begin{array}{c}M_{R} \\
(\mu g)\end{array}$ & $\begin{array}{c}C_{S} \\
\left(\mu g / m^{2}\right)\end{array}$ & $\begin{array}{c}M_{\mathrm{T}} \\
(\mathrm{mg})\end{array}$ \\
\hline OTP-3A & 1.0 & ND & - & - & ND & - & - & 1.6 & 1.6 & 0.82 \\
\hline OTP-6A & 1.1 & ND & - & - & ND & - & - & 1 & 0.94 & 0.52 \\
\hline Plume 6 & 1375 & & & & & & & & & \\
\hline Crater & 0.20 & ND & - & - & ND & - & - & 12 & 61 & 0.89 \\
\hline LIS-1 & 1.3 & ND & - & - & 4.0 & 3.4 & 4.7 & 1.3 & 1.1 & 1.5 \\
\hline LIS-2 & 1.2 & ND & - & - & 1.9 & 1.5 & 2.0 & 2 & 1.6 & 2.2 \\
\hline LIS-3 & 1.6 & 5.1 & 3.2 & 4.4 & 7.1 & 4.5 & 6.1 & 3.8 & 2.3 & 3.2 \\
\hline OTP-3A & 1.0 & ND & - & - & 2.2 & 2.2 & & 2.3 & 2.3 & 1.2 \\
\hline Plume 7 & 1180 & & & & & & & & & \\
\hline LIS-1 & 1.1 & ND & - & - & 4.0 & 4.2 & 4.9 & 4.1 & 4.2 & 5.0 \\
\hline LIS-2 & 1.0 & 2.6 & 2.5 & 3.0 & 17 & 16 & 19 & 3.4 & 3.2 & 3.8 \\
\hline LIS-Lt & 0.83 & ND & - & - & ND & - & - & 4.2 & 5.1 & 3.9 \\
\hline LIS-Med & 0.52 & 2.3 & 4.4 & 1.4 & 2.8 & 5.4 & 1.7 & 5.1 & 9.8 & 3.1 \\
\hline LIS-Dk & 0.45 & 3.2 & 7.1 & 0.69 & 94 & 94 & 9.1 & 6.7 & 15 & 1.4 \\
\hline OTP-20R & 0.78 & ND & - & - & ND & - & - & 4.1 & 5.2 & 1.9 \\
\hline
\end{tabular}




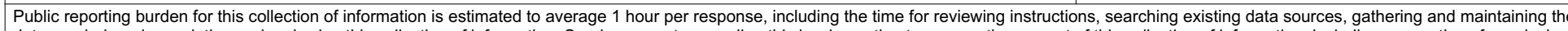

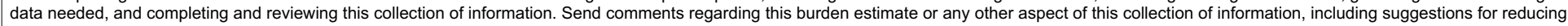



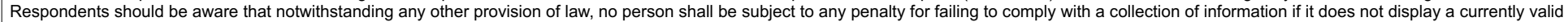
OMB control number. PLEASE DO NOT RETURN YOUR FORM TO THE ABOVE ADDRESS.
1. REPORT DATE (DD-MM-YY)
2. REPORT TYPE
DATES COVERED (From - To)

April 2005

Technical Report

4. TITLE AND SUBTITLE

An Examination of Protocols for the

Collection of Munitions-Derived

Explosives Residues on Snow-Covered Ice

5a. CONTRACT NUMBER

6. AUTHOR(S)

Michael R. Walsh, Marianne E. Walsh,

Charles A. Ramsey, and Thomas F. Jenkins

5b. GRANT NUMBER

5c. PROGRAM ELEMENT NUMBER

5d. PROJECT NUMBER

5e. TASK NUMBER

5f. WORK UNIT NUMBER

7. PERFORMING ORGANIZATION NAME(S) AND ADDRESS(ES)

8. PERFORMING ORGANIZATION REPORT

U.S. Army Engineer Research and Development Center

Cold Regions Research and Engineering Laboratory

72 Lyme Road

ERDC/CRREL TR-05-8

Hanover, New Hampshire 03755

10. SPONSOR / MONITOR'S ACRONYM(S)

9. SPONSORING/MONITORING AGENCY NAME(S) AND ADDRESS(ES)

U.S. Army Corps of Engineers

Washington, DC 20314-1000

11. SPONSOR / MONITOR'S REPORT NUMBER(S)

\section{DISTRIBUTION / AVAILABILITY STATEMENT}

Approved for public release; distribution is unlimited.

Available from NTIS, Springfield, Virginia 22161.

\section{SUPPLEMENTARY NOTES}

\section{ABSTRACT}

Range contamination and sustainability are major issues for the United States military. Training is a critical factor in force readiness, and the availability of ranges is crucial to this need. To determine the impact of training on ranges, data are required on the deposition of explosives residues from live-fire and blow-in-place detonation of munitions. A method of sampling on snow-covered ranges, the discrete sampling method, was developed by the Army's Cold Regions Research and Engineering Laboratory to determine residues from the detonation of munitions. Although very effective, it requires the collection of many large samples, resulting in labor-intensive field operations and much processing and analysis work in the laboratory. By examining sampled locations within detonation plumes, it appears that collection bias may be affecting the results. There was also no methodology for quality assurance in the collection of the samples. We have examined the process currently in use and carried out a series of experiments to determine whether bias and sample quality issues are present in the sampling technique. Alternative methods of sample collection that afford a greater opportunity for quality control were examined and compared to the discrete sampling method. The recommended alternative sampling protocol is to collect multi-increment samples, and experimental results using this method are presented.

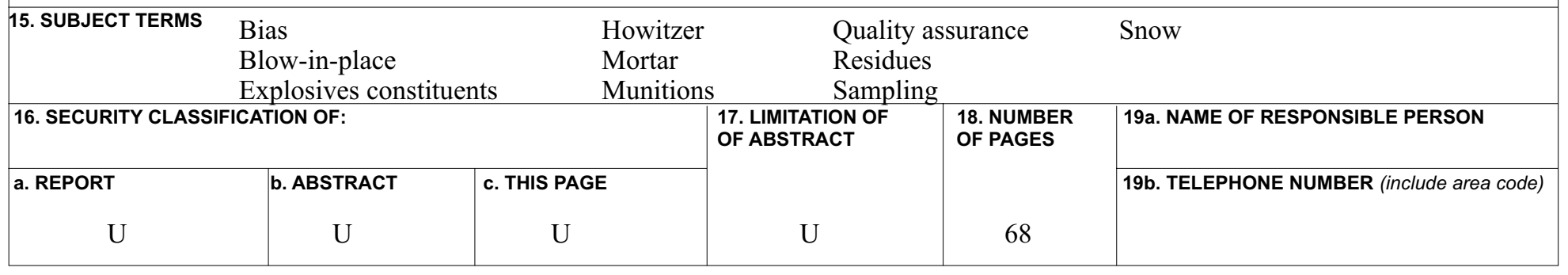

